\title{
Cortical Control of Affective Networks
}

\author{
Sunil Kumar, ${ }^{1}$ Sherilynn J. Black, ${ }^{1}$ Rainbo Hultman, ${ }^{5}$ Steven T. Szabo, ${ }^{1}$ Kristine D. DeMaio, ${ }^{5}$ Jeanette Du, ${ }^{5}$ \\ Brittany M. Katz, ${ }^{1}$ Guoping Feng, ${ }^{6}$ Herbert E. Covington III, ${ }^{3,5 *}$ and Kafui Dzirasa ${ }^{1,2,3,4 *}$ \\ ${ }^{1}$ Department of Psychiatry and Behavioral Sciences, ${ }^{2}$ Center for Neuroengineering, and ${ }^{3}$ Duke Institute for Brain Sciences, Duke University Medical Center, \\ Durham, North Carolina 27710, Departments of ${ }^{4}$ Biomedical Engineering and Neurobiology and ${ }^{5}$ Psychology and Neuroscience, Duke University, Durham, \\ North Carolina 27708, and ' Department of Brain and Cognitive Sciences, McGovern Institute for Brain Research at Massachusetts Institute of Technology, \\ Cambridge, Massachusetts 02139
}

Transcranial magnetic stimulation and deep brain stimulation have emerged as therapeutic modalities for treatment refractory depression; however, little remains known regarding the circuitry that mediates the therapeutic effect of these approaches. Here we show that direct optogenetic stimulation of prefrontal cortex (PFC) descending projection neurons in mice engineered to express Chr2 in layer $\mathrm{V}$ pyramidal neurons (Thy1-Chr2 mice) models an antidepressant-like effect in mice subjected to a forced-swim test. Furthermore, we show that this PFC stimulation induces a long-lasting suppression of anxiety-like behavior (but not conditioned social avoidance) in socially stressed Thy1-Chr2 mice: an effect that is observed $>10 \mathrm{~d}$ after the last stimulation. Finally, we use optogenetic stimulation and multicircuit recording techniques concurrently in Thy1-Chr2 mice to demonstrate that activation of cortical projection neurons entrains neural oscillatory activity and drives synchrony across limbic brain areas that regulate affect. Importantly, these neural oscillatory changes directly correlate with the temporally precise activation and suppression of limbic unit activity. Together, our findings show that the direct activation of cortical projection systems is sufficient to modulate activity across networks underlying affective regulation. They also suggest that optogenetic stimulation of cortical projection systems may serve as a viable therapeutic strategy for treating affective disorders.

\section{Introduction}

Major depressive disorder (MDD) is a complex multifactorial neuropsychiatric illness characterized by profound changes in mood, sleep, affect, and interests (American Psychiatric Association, 2000; Akil et al., 2010). At least 4\% of the United States population is affected by MDD each year, and $17 \%$ of the population is expected to suffer from MDD in their lifetime (Blazer et al., 1994; Kessler et al., 1994). The disorder is associated with significant morbidity and mortality and is projected to become the second leading cause of disability worldwide by 2030 (Mathers and Loncar, 2006). Furthermore, the disorder is highlighted by a heterogeneous presentation of symptoms, which makes its characterization, evaluation, and treatment difficult.

Functional changes across vast circuits spanning multiple cortical and subcortical brain areas are thought to contribute to the

Received Jan. 6, 2012; revised Nov. 3, 2012; accepted Nov. 11, 2012.

Author contributions: G.F., H.E.C., and K.Dz. designed research;S.K., S.J.B., R.H., K.D.De., J.D., B.M.K., H.E.C., and K.Dz. performed research; K.Dz. contributed unpublished reagents/analytic tools; S.J.B., R.H., K.D.De., J.D., H.E.C., and K.Dz. analyzed data; S.K., S.J.B., R.H., S.T.S., B.M.K., G.F., H.E.C., and K.Dz. wrote the paper.

This work was supported by National Institute of Mental Health Grants P50MH060451-09S1 and R37MH073853 (K.Dz.), American Recovery and Reinvestment Act Grant RC1-MH088434 (G.F.), and a Duke Institute for Brain Sciences Research Incubator Award (H.E.C. and K.Dz.). A special thanks to Freeman Hrabowski, Robert and Jane Meyerhoff, and the MeyerhoffScholarship Program. We thank Joao Peca for assistance with laser setup, Raag Airan, and Karl Deisseroth for helpful suggestions with optogenetic stimulation.

*H.E.C. and K.Dz. contributed equally to this work.

Correspondence should be addressed to Dr. Kafui Dzirasa, Department of Psychiatry and Behavioral Sciences, Duke University Medical Center, Box 3209, 327 Bryan Research Building, Durham, NC 27710. E-mail: kafui.dzirasa@duke.edu.

DOI:10.1523/JNEUROSCI.0092-12.2013

Copyright $\odot 2013$ the authors $\quad 0270-6474 / 13 / 331116-14 \$ 15.00 / 0$ symptoms comprising MDD (Drevets, 2001; Liotti and Mayberg, 2001). Nevertheless, the exact neurobiological underpinnings of depressive symptoms and various therapeutic modalities remain to be clarified. The primary treatment modalities for individuals suffering from MDD include pharmacotherapy, psychotherapy, and electroconvulsive therapy (ECT). However, these modalities fail to fully ameliorate symptoms in up to $50 \%$ of depressed individuals (Nestler et al., 2002), and lifetime recurrence rates after recovery are estimated to be $>35-50 \%$ (Mueller et al., 1999; Eaton et al., 2008). Novel approaches, including deep brain stimulation (DBS) and transcranial magnetic stimulation (TMS), have recently emerged as viable therapeutic options (Ressler and Mayberg, 2007; George et al., 2010). Both DBS and TMS function by stimulating cortical brain areas (George et al., 1999; Mayberg et al., 2005), either through the direct delivery of current via surgically implanted stimulating electrodes (DBS) or through the transcranial modulation of neural activity via the external manipulation of magnetic fields (TMS); however, little remains known about the brain network mechanisms whereby these modalities mediate their antidepressant effect.

The prevailing hypothesis is that DBS and TMS mediate their antidepressant effect by directly activating descending prefrontal cortex (PFC) signals (Mayberg, 2009). These descending brain signals then modulate dynamic activity across subcortical limbic circuits (i.e., top-down control) that are responsible for reward processing, fear and anxiety, motivation, and circadian regulation. Unfortunately, it has been difficult to generate concrete evidence that supports this hypothesis given the complexity of recording the activity of widely distributed limbic circuits during 
a

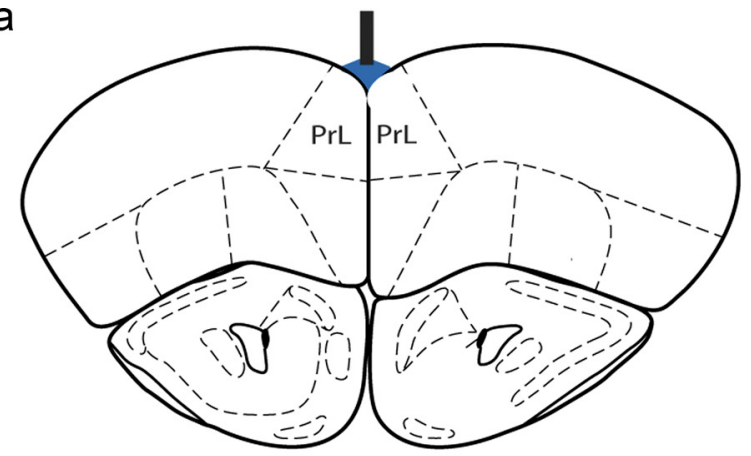

b
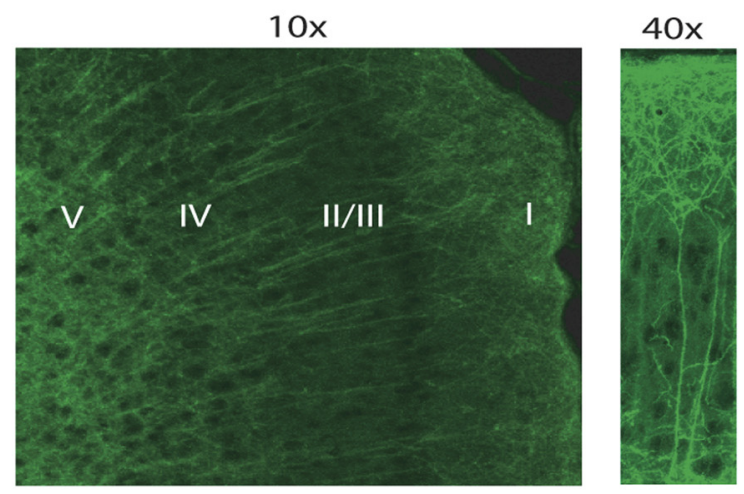

C

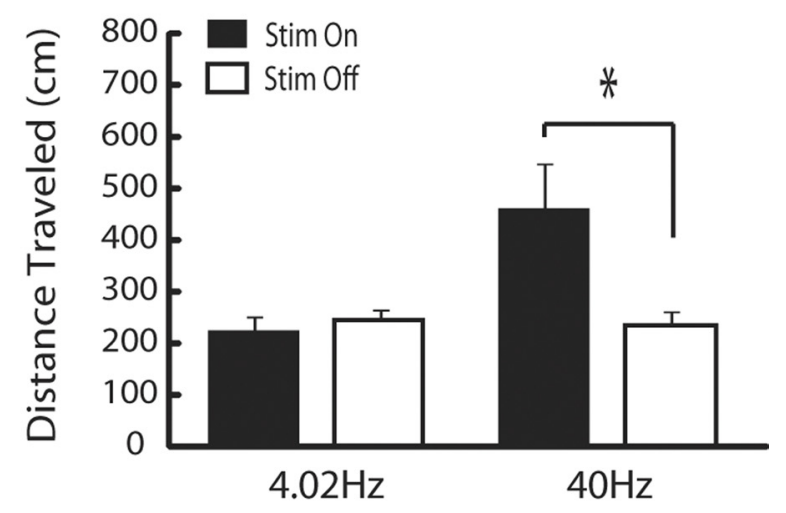

d

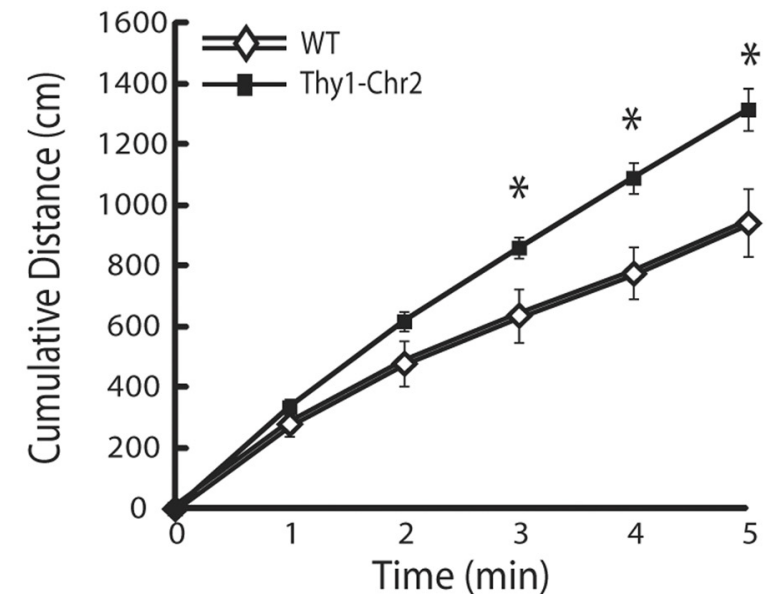

Figure 1. High-frequency PFC stimulation induces hyperactivity. $\boldsymbol{a}$, Cortical stimulation targeting approach used for behavioral and neurophysiological experiments. $\boldsymbol{b}$, Anterior PrL expression pattern of Chr2 in Thy1-Chr2 (line 18) mice. Chr2 labeling was observed in the cell bodies of layer $V$ neurons (left) and their apical dendrites. High-resolution image of an apical dendrite of a layer V pyramidal neuron (right). c, Thy1-Chr2 mice were placed in an open field, and locomotor profiles were recorded during PrL stimulation with a prerecorded PrL neuron direct activation of descending cortical pathways in both healthy and depressed individuals. Furthermore, although animal studies have been used to generate a great deal of insight into the mechanism of action of several treatment modalities for depressed individuals, including pharmacotherapy and ECT (Nestler et al., 2002; Jinno and Kosaka, 2009), neuroscience tools that allow activity to be quantified across intact brain circuits in animals during the manipulation of activity across specific cell types have been lacking.

Here we empirically assess whether direct optogenetic stimulation of cortical projection neurons is sufficient to modify depression-related behaviors in mice. Furthermore, we use multicircuit neurophysiological recording techniques and optogenetic stimulation concurrently to examine the effect of cortical layer $\mathrm{V}$ activation on neural activity across distributed limbic networks responsible for affective regulation.

\section{Materials and Methods}

Animal care and use. Male mice were used for all experiments. ThylChR2-eYFP line 18 mice (Thy1-Chr2 mice) were generated as described previously (Arenkiel et al., 2007). These mice are also commercially available through The Jackson Laboratories [B6.Cg-Tg(Thy1-Chr2/ EYFP)18Gfng/J]. Thy1-Chr2 (line 18) mice express the ChR2-YFP fusion protein in layer $\mathrm{V}$ cortical neurons [including prelimbic cortex $(\operatorname{PrL})$; see Figure 1], CA1 and CA3 pyramidal neurons of the hippocampus, cerebellar mossy fibers, neurons in the thalamus, neurons in the midbrain and brainstem, and the olfactory bulb mitral cells. Consistent with previous reports (Arenkiel et al., 2007; Kahn et al., 2011), pyramidal neurons in layer 2/3 of PrL do not express Chr2 in the Thy1-Chr2 line 18 mice. Mice were housed on a $12 \mathrm{~h}$ light/dark cycle, three to five per cage and maintained in a humidity- and temperature-controlled room with food and water available ad libitum. Behavioral experiments were initiated after a 1 week recovery and were conducted during the dark cycle. Neurophysiological experiments were initiated after a 2-4 week recovery and were conducted during the light cycle while animals were in their home cage. All of the implanted Thy1-Chr2 animals were subjected to a 20 min recording session wherein the stimulating laser was driven at 0.1 Hz. Eight of the implanted Thy1-Chr2 mice were also subjected to a 2 min recording sessions in which $\sim 30 \mathrm{~s}$ of baseline neurophysiological activity was acquired before and after $60 \mathrm{~s}$ of continuous cortical stimulation using an exogenous spike pattern.

All studies were conducted with approved protocols from the Duke University Institutional Animal Care and Use Committees and were in accordance with the National Institutes of Health Guidelines for the Care and Use of Laboratory Animals.

Surgery. Four- to eight-month-old Thy1-Chr2 mice were anesthetized with ketamine $(100 \mathrm{mg} / \mathrm{kg})$ and xylazine $(10 \mathrm{mg} / \mathrm{kg})$ and placed in a stereotaxic device, and metal ground screws were secured to the skull above cerebellum and anterior cranium. For physiology experiments, a total of 32-46 tungsten microwires were arranged in bundle arrays of four to eight wires (each wire separated by at least $250 \mu \mathrm{m}$ ) and implanted as shown in Table 1 (all coordinates are measured from bregma).

Full details of the procedures for electrode construction and surgical implantation have been described previously (Dzirasa et al., 2011a).

Twelve Thy1-Chr2 mice were implanted with recording electrodes in all four brain areas, and one wild-type (WT) mouse was implanted in PrL. A mono fiber-optic cannula coupled to a $2.5 \mathrm{~mm}$ metal ferrule [numerical aperture 0.22; $100 \mu \mathrm{m}$ (inner diameter), $125 \mu \mathrm{m}$ buffer

$\leftarrow$

pattern $(4.02 \mathrm{~Hz}$ ) or at $40 \mathrm{~Hz}$ ( $5 \mathrm{~ms}$ pulse width). The distance traveled during the 1 min stimulation intervals was compared with the distance traveled during the $1 \mathrm{~min}$ intervals after stimulation using a Student's $t$ test. PrL stimulation at $40 \mathrm{~Hz}$ induced hyperactivity, whereas stimulation using the PrL neuron pattern did not. ${ }^{*} p<0.025 ; n=6$ Thy1-Chr2 mice. $\boldsymbol{d}$, Open-field locomotor profiles in WT and Thy1-Chr2 mice during 5 min PrL stimulation at 4.02 Hz. ${ }^{*} p<0.05$ using Student's $t$ test; $n=6$ mice per genotype. 
Table 1. Implantation coordinates measured from bregma

\begin{tabular}{llcc}
\hline Area & AP $(\mathrm{mm})$ & $\mathrm{ML}(\mathrm{mm})$ & DV $(\mathrm{mm})$ \\
\hline PrL & +2.65 & \pm 0.25 & -0.8 \\
NAC & +1.25 & +1.15 & -3.9 \\
BA & -1.58 & 2.5 & 4.75 \\
VTA & -3.3 & +0.3 & -4.25 \\
\hline
\end{tabular}

(outer diameter); MFC_100/125-0.22; Doric Lenses] was built directly into the PrL cortex bundle. The tip of the fiber was secured $800 \mu \mathrm{m}$ above the tip of the tungsten microwires such that the optical fiber lay just above the dura above the midline after implantation. Implanted electrodes were anchored to ground screws using dental acrylic. For all behavioral experiments, 8- to 10-week-old Thy1-Chr2 mice and their littermate controls $(N=42$ mice) were implanted with a single mono fiber-optic cannula in PrL $250 \mu \mathrm{m}$ below the dura [anteroposterior (AP), $2.65 \mathrm{~mm}$; mediolateral (ML), $0 \mathrm{~mm}$ to bregma]. All behavioral experiments were initiated after a $7 \mathrm{~d}$ recovery period after surgery. Note that, for our behavioral experiments using chronic subordination stress, mice were implanted with stimulating electrodes before being exposed to the stress paradigm. For c-fos experiments, 18- to 24-week-old Thy1-Chr2 mice $(n=12)$ were implanted with a single mono fiber-optic cannula in PrL $250 \mu \mathrm{m}$ below the dura (AP, $2.65 \mathrm{~mm}$; ML, $0 \mathrm{~mm}$ to bregma). All behavioral experiments were initiated after a 7-14 d recovery period after surgery.

In vivo light stimulation. Laser output was controlled by digital input from the Cerebus acquisition system using custom-written MATLAB scripts for neurophysiology experiments and during the forced-swim test. For chronic stimulation experiments, an arbitrary function generator (model 33210A; Agilent Technologies) was used to drive the laser. The stimulation pattern used for both systems was identical. For all experiments presented in the main text, each spike of the stimulus train initiated a $10 \mathrm{~ms}$ light pulse. The prerecorded neuron firing pattern used to drive the laser was based on a PFC layer $\mathrm{V}$ pyramidal neuron. This neuron exhibited a mean firing rate $(4.02 \mathrm{~Hz})$, consistent with the mean firing rate of PFC pyramidal neurons described in other studies (Jones and Wilson, 2005). Our physiology experiments were performed with a laser power of $2.5 \mathrm{~mW}$ (corresponding to $250 \mathrm{~mW} / \mathrm{mm}^{2}$ ). The tip of the fiber-optic cannula was located above the superior sagittal sinus and above the dura. Assuming the attenuation of light above the gray matter is predicted by a simple conical model for diffusion through saline (Yizhar et al., 2011), we expect a maximum illumination of $9.2 \mathrm{~mW} / \mathrm{mm}^{2}$ over a cortical surface area of $0.217 \mathrm{~mm}^{2}$ and a maximum light spread of $300 \mu \mathrm{m}$. All behavioral experiments were conducted with a laser power of $2.0 \mathrm{~mW}$ (corresponding to $200 \mathrm{~mW} / \mathrm{mm}^{2}$ ), with the optic stimulating fiber placed $250 \mu \mathrm{m}$ below the dorsal surface of the dura at the midline. For these experiments, we expect a maximum illumination of $23.3 \mathrm{~mW} /$ $\mathrm{mm}^{2}$ over a cortical surface area of $0.102 \mathrm{~mm}^{2}$ and a maximum light spread of $400 \mu \mathrm{m}$. For the neurophysiological anatomical control experiment, the optic fiber was placed directly on the brain surface directly above primary sensory cortex (S1) [AP, $-0.1 \mathrm{~mm}$; ML, +3.25 mm; dorsoventral (DV), 0.75 from bregma], and light stimulation was delivered at $20 \mathrm{~mW} / \mathrm{mm}^{2}$. Laser output was measured using a Power meter (PM100D; Thorlabs).

Controlling for tissue-heating effects during high-intensity cortical stimulation. Five minutes of high-intensity light stimulation has the potential to damage cortical tissues and to induce physiological and behavioral changes. To account for this potential confound, the tip of the optic stimulating fiber was placed into the superior sagittal sinus such that there was constant blood flow over the stimulated cortical tissue. This approach was used to increase the likelihood for the dissipation of heat that resulted from high-intensity light stimulation. Second, all control experiments were performed in WT littermates that received identical cortical stimulations, and behavioral comparisons were made across genotype.

Forced-swim test. Thy1-Chr2 mice and their WT littermate controls were anesthetized with isoflurane and connected to an optic stimulating fiber. After a 15 min recovery period, mice were placed into a $4000 \mathrm{ml}$ graduated beaker filled with water $\left(26^{\circ} \mathrm{C}\right)$ to a depth of 7 inches. The mice remained in the water for 5 min during cortical stimulation and were then removed and allowed to dry in a clean dry cage before they were returned to their home cage. The water was changed between each subject. Mice were monitored using a side-mounted camera, and video data were scored for the total time each mouse spent immobile. The experimenter scoring the behavior was blind to the genotype of the mice, and immobility was defined as no volitional body or limb movement. Additional control experiments were performed in unimplanted animals. Data were analyzed using a two-way ANOVA, followed by a Bonferroni's-corrected Student's $t$ test at $\alpha=0.05$.

Open-field test. Mice were anesthetized with isoflurane and connected to an optic stimulating fiber. After a 15 min recovery period, mice were placed into a $10.75 \times 10.75$-inch open-field test environment (MEDOFA-MS; Med Associates). For our initial experiments, six Thy1-Chr2 mice were placed in an open field, and locomotor profiles were recorded for $5 \mathrm{~min}$. Light stimulations were delivered at $40 \mathrm{~Hz}$ ( $5 \mathrm{~ms}$ pulse width) and $4.02 \mathrm{~Hz}$ (prerecorded neuron pattern) for 1 min during minutes 2 and 4 of the open-field test. Three Thy1-Chr 2 mice received the $40 \mathrm{~Hz}$ stimulus first, and the other three mice received the $4.02 \mathrm{~Hz}$ stimulus first. Animals were used only once, and statistical comparisons of locomotor behavior were made between the 1 min period in which each animal received PFC stimulation and the 1 min period immediately after stimulation using a paired Student's $t$ test at $\alpha=0.05$.

For the second set of experiments, locomotor profiles were monitored in Thy1-Chr2 and WT control mice while light stimulation was delivered using the $1 \mathrm{~min}$ prerecorded PrL neuron pattern repeated across the 5 min test period. Additional control experiments were performed in unimplanted animals. Data were analyzed using a two-way ANOVA, followed by a Bonferroni's-corrected Student's $t$ test at $\alpha=0.05$.

Chronic subordination stress and chronic PrL stimulation. Thy1-Chr2 and WT littermate control mice were implanted with stimulating fibers and $10 \mathrm{~d}$ later subjected to $15 \mathrm{~d}$ of chronic social defeat stress as described previously (Berton et al., 2006; Covington et al., 2010). Briefly, mice were exposed to a novel CD1 aggressor for $5 \mathrm{~min}$ daily and then separated from the aggressor behind a protective barrier for the remainder of the day. During bouts of exposure to the CD1 mice, hallmark behavioral signs of subordination stress were observed, including escape, submissive postures (i.e., defensive upright and supine), and freezing. Immediately after the last social defeat episode, all mice were housed individually. Forty-eight hours after the last social defeat encounter, mice received 5 min of daily cortical stimulation using the same prerecorded PrL neuron pattern used for our physiology experiments. All animals were stimulated in their home cage for 14 days. Ten to $14 \mathrm{~d}$ after the last cortical stimulation, mice were tested for social avoidance and anxiety-related behaviors. Single-housed C57BL/6J mice were used as an additional control for the social interaction test.

Social interaction test. Social interaction was measured as described previously (Berton et al., 2006). Briefly, mice were placed within a novel arena with a small animal cage located at one end. Each socially stressed mouse's movement was monitored for $5 \mathrm{~min}$ in the presence of a CD1 mouse. Locomotor activity measurements (distance traveled) and information pertaining to the duration spent within the interaction zone was quantified using Ethovision 3.0 software. Data were analyzed using a Student's $t$ test at $\alpha=0.05$.

Elevated plus maze test. The elevated plus maze (EPM) was designed using black Plexiglas fitted with white-bottom surfaces to provide contrast, and tests were conducted as described previously (Monteggia et al., 2007). Briefly, mice were placed in the center of the plus maze and allowed to freely explore the maze for $5 \mathrm{~min}$ under well-lit conditions (Covington et al., 2010). The position of each mouse in the maze was monitored with video tracking equipment (Ethovision) and a ceiling-mounted camera. Data were analyzed using a Student's $t$ test at $\alpha=0.05$.

Neurophysiological data acquisition. Neuronal activity was sampled at $30 \mathrm{kHz}$, high-pass filtered at $250 \mathrm{~Hz}$, sorted online, and stored using the Cerebus acquisition system (Blackrock Microsystems). Neuronal data were referenced online against a wire within the same brain area that did not exhibit a signal-to-noise ratio greater than 3:1. At the end of the recording, cells were sorted again using an offline sorting algorithm 

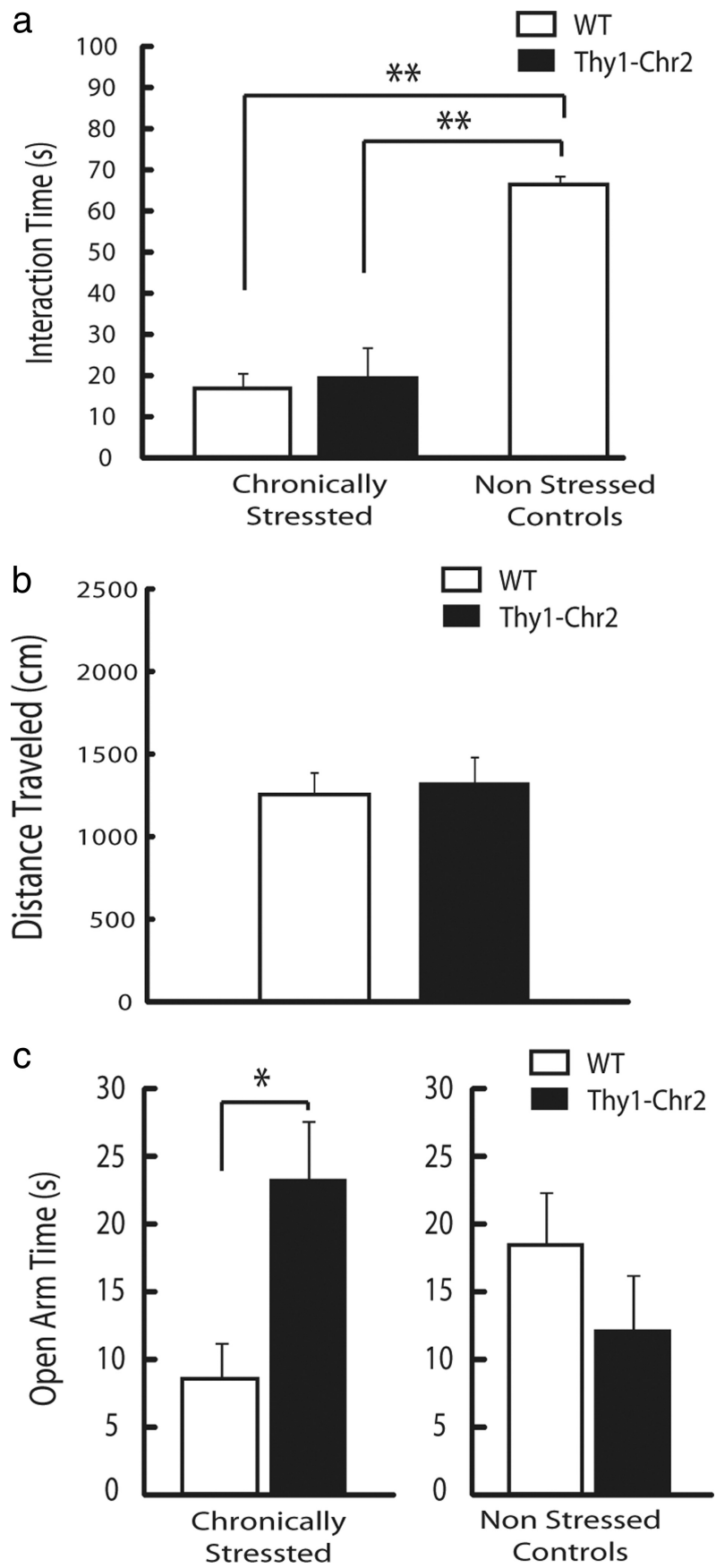

Figure 2. Antidepressant-like effect of chronic cortical stimulation in chronically stressed mice. $\boldsymbol{a}$, Thy1-Chr2 mice exposed to chronic subordination stress displayed similar interaction times as their WT littermates during the social interaction test after chronic cortical stimulation. Chronically stressed mice exhibited significantly lower social interaction scores than nonstressed nonstimulated single-housed control mice. ${ }^{* *} p<0.001$ using Student's $t$ test; $n=$ 6-7 per genotype. $\boldsymbol{b}$, Thy1-Chr2 mice exposed to chronic subordination stress exhibited similar open-field exploration profiles as their chronically stressed WT littermates after chronic cortical stimulation. c, Chronically stressed and chronically stimulated Thy1-Chr2 mice spent more time in the open arm of an EPM compared with their WT littermate controls. ${ }^{*} p<0.05$ using Student's $t$ test; $n=7$ per genotype (left). No significant differences in open arm time were observed between single-housed (nonstressed) Thy1-Chr2 and WT control mice after chronic stimulation. $P<0.05$ using Student's $t$ test; $n=6-7$ per genotype.

(Plexon) to confirm the quality of the recorded cells. Local field potentials (LFPs) were bandpass filtered at $0.3-500 \mathrm{~Hz}$ and stored at $1000 \mathrm{~Hz}$. An online $60 \mathrm{~Hz}$ line noise-cancelation algorithm was applied to neurophysiological signals at the time of acquisition, and all neurophysiologi- cal recordings were referenced to a ground wire connected to both ground screws. Notably, wires tested from the two screws were isoelectric, demonstrating that ground loops were not introduced by this design.

Determination of the effect of cortical stimulation on LFP oscillatory power. A second sliding window Fourier transform was applied to the LFP signal using MATLAB (MathWorks). Parameters were chosen to allow a frequency and temporal resolution of $0.125 \mathrm{~Hz}$ and $500 \mathrm{~ms}$, respectively. The mean oscillatory power was then calculated for each frequency band of interest for the time intervals before, during, and after cortical stimulation. To determine the effect of cortical stimulation on limbic oscillatory power, oscillatory power observed during cortical stimulation was averaged across all LFPs recorded from the same area within a mouse and compared with the mean of the oscillatory power observed before and after cortical stimulation using a paired $t$ test at $\alpha=0.05$, followed by a false discovery rate (FDR) correction (Benjamini et al., 2001) within each frequency band $(n=8$ mice for all areas).

Determination of the effect of cortical stimulation on cross-area spectral synchrony. Two LFPs were randomly chosen from each recorded brain area, and four cross-area synchrony functions were calculated for each LFP pair using the MATLAB mscohere function. Parameters were chosen to allow a frequency and temporal resolution of $0.125 \mathrm{~Hz}$ and $500 \mathrm{~ms}$, respectively. To determine the effect of cortical stimulation on limbic synchrony, coherence values observed during cortical stimulation were averaged across the four cross-area synchrony functions calculated for each brain area pair and compared to the mean of the coherence values observed before and after cortical stimulation using a paired $t$ test at $\alpha=0.05$, followed by an FDR correction for the five brain area pairs within each frequency band $(n=8$ mice for all other comparisons).

Determination of the effect of cortical stimulation on limbic unit activity. Neuronal activity was recorded for $20 \mathrm{~min}$ while cortex was stimulated at $0.1 \mathrm{~Hz}$. Neuronal activity referenced to the light onset was averaged in 20 ms bin, shifted by $1 \mathrm{~ms}$, and averaged across the 120 trials to construct the perievent time histogram. Distributions of the histogram from the $[-5000,-2000 \mathrm{~ms}]$ interval were considered baseline activity. We then determined which $20 \mathrm{~ms}$ bins slid in $1 \mathrm{~ms}$ steps during an epoch spanning from the $[0,300 \mathrm{~ms}]$ interval met the criteria for modulation by cortical stimulation. A unit was considered to be modulated by cortical stimulation if at least 20 bins had firing rates either larger than a threshold of $99 \%$ above baseline activity or smaller than a threshold of $94 \%$ below baseline activity (several neurons displayed both temporally delayed increases and decreases in their firing rates after single-pulse cortical stimulation). This approach was modeled after perievent analytical approaches used in other published studies (Jin and Costa, 2010). Correlations between peristimulus firing rate time histograms and mean LFP evoked responses were calculated for the $[0,100 \mathrm{~ms}]$ interval using a linear regression at $\alpha=0.05$.

Excitotoxic lesions. Ibotenic acid was used to induce selective excitotoxic lesions in the PrL of Thyl mice (Hamani et al., 2010). Briefly, ibotenic acid (Abcam) was dissolved in PBS, $\mathrm{pH} 7.4$, containing $0.01 \%$ of acetic acid. Mice were anesthetized and placed in a stereotaxic device as described above. Next, $2 \mu \mathrm{g}$ of ibotenic acid (dissolved in $0.4 \mu \mathrm{l}$ of PBS) was injected at four target sites using a $5 \mu$ l Hamilton syringe (AP, 2.4 or $2.9 \mathrm{~mm}$; ML, +0.35 and $-0.35 \mathrm{~mm}$; DV, $0.8 \mathrm{~mm}$ measured from bregma). The solution was injected at a rate of $0.1 \mu \mathrm{l} / \mathrm{min}$, and the needle was left in place for $5 \mathrm{~min}$ after each injection to ensure the diffusion of the solution in the brain tissue. Mice were then returned to their home cage, and electrodes were implanted 2 weeks later as described above. One Thy1-Chr2 mouse was also injected unilaterally with ibotenic acid and used for the generation of histological images.

Histology and immunohistochemistry. To characterize the PrL Chr2 expression pattern in the Thy1-Chr2 (line 18) mice, an 8-week-old mouse was perfused, and its brain was incubated for $3 \mathrm{~d}$ in $4 \%$ paraformaldehyde (PFA), followed by $24 \mathrm{~h}$ in $30 \%$ sucrose. Free-floating sections $(50 \mu \mathrm{m})$ were cut using a microtome, mounted on glass slides, and examined near the PrL ( $+2.6 \mathrm{~mm}$ AP to bregma) for the presence of YFP to identify expression of $\mathrm{Chr} 2$ as well as DAPI to identify nuclei using a 
Carl Zeiss LSM 510 inverted confocal microscope in wide-field fluorescence and laser scanning confocal modes. For immunohistochemistry studies, 12 single-housed 20- to 24-week-old male Thy1-Chr2 mice were implanted with fiber optic stimulating cannula in PrL. After a 7-14 d recovery period, mice were anesthetized under isoflurane, and a fiber optic patchcord was connected to the implanted optical fiber. One hour later, six mice were stimulated for $5 \mathrm{~min}$ at a light intensity of $250 \mathrm{~mW} /$ $\mathrm{mm}^{2}$ with the same neuron-based firing pattern used for our behavioral experiments. The remaining six mice were stimulated at a light intensity of $0 \mathrm{~mW} / \mathrm{mm}^{2}$ (i.e., nonstimulated controls). One hour after stimulation, all mice were perfused, and their brains were incubated for $3 \mathrm{~d}$ in $4 \%$ PFA, followed by $24 \mathrm{~h}$ immersion in $30 \%$ sucrose. Sections were sliced at $50 \mu \mathrm{m}$ and stained with an anti-c-fos antibody (lot D00119667; Calbiochem) using the following protocol: slices were blocked in blocking buffer containing $0.25 \%$ Triton $\mathrm{X}-100,3 \%$ goat serum (overnight at $4^{\circ} \mathrm{C}$ ), incubated at room temperature for $1 \mathrm{~h}$ in a 1:20,000 dilution of c-fos primary antibody, followed by incubation for $72 \mathrm{~h}$ at $4^{\circ} \mathrm{C}$. Slices were then rinsed in blocking buffer three times for $2 \mathrm{~h}$ at $4^{\circ} \mathrm{C}$, followed by an overnight incubation in a secondary antibody (1:1000, Alexa Fluor-555 goat anti-rabbit; Invitrogen) at $4^{\circ} \mathrm{C}$, followed by two washes in blocking buffer and one wash in PBS at $4^{\circ} \mathrm{C}$ for $2 \mathrm{~h}$ each. Images were captured on a Nikon Eclipse 80i fluorescence microscope at $40 \times$ magnification. Nonspecific staining levels were determined by imaging slices processed in parallel in the absence of the primary antibody; this background fluorescence was filtered out of all c-fos-stained slices. All cells with at least $50 \%$ of the nucleus having fluorescence intensity above the nonspecific threshold were considered positive for c-fos. Threshold and pixel intensities were analyzed using Nikon Elements Basic software. Three fields of highest intensity were imaged for each region [PrL, nucleus accumbens (NAc), basal amygdala (BA), and ventral tegmental area (VTA)] of each of three brains per condition. The number of neurons that expressed c-fos in each brain region was compared between stimulated and nonstimulated mice using a $t$ test.

Statistics. All data in the main text are presented as mean \pm SEM.

\section{Results}

\section{High-frequency stimulation of PFC layer V neurons induces hyperactivity}

Non-layer-selective activation of PFC pyramidal neurons has been shown recently to alter locomotor behavioral profiles in mice infected with Chr2 virus (Anikeeva et al., 2012). Thus, we tested the effect of direct PFC layer V stimulation on forward locomotion (Fig. 1). Six Thy1-Chr2 mice were implanted with stimulating fibers in anterior PFC, and animals were stimulated as they explored an open field. Each mouse was subjected to a 40 $\mathrm{Hz}$ stimulation pattern and a stimulation pattern based on the firing pattern of a previously recorded PFC pyramidal neuron (mean stimulation rate of $4.02 \mathrm{~Hz}$ ). Consistent with previous reports in mice infected with Chr2 virus (Anikeeva et al., 2012), b

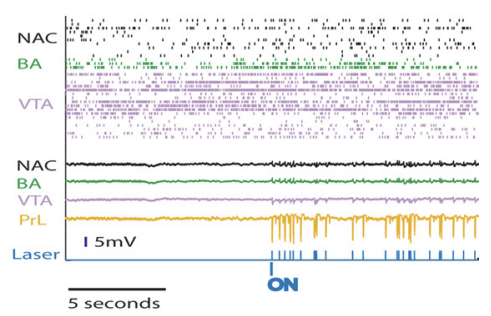

d

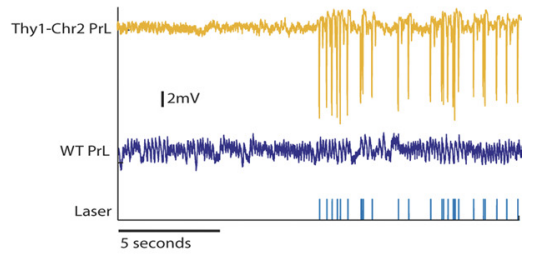

NAC

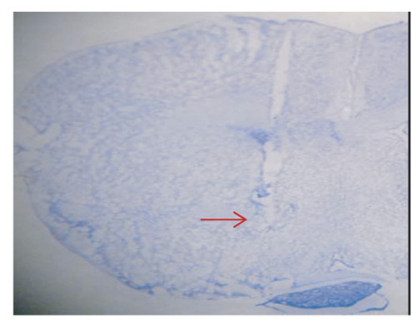

VTA

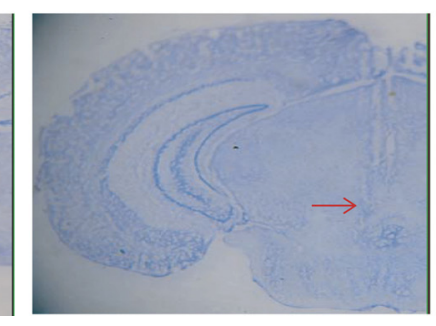

PrL

BA

Figure 3. Neurophysiological recordings during optogenetic stimulation of cortical projection neurons. $\boldsymbol{a}$, Diagram of limbic with a $10 \mathrm{~s}$ trace of neurophysiological activity recorded at the offset of cortical stimulation. c, Sixty second rate

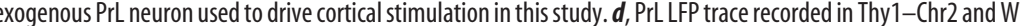
mouse during cortical stimulation. Note that laser pulses do not generate the large-amplitude traces in WT mice during cortical stimulation. $\boldsymbol{e}$, Histological images showing representative electrode lesion tracks.

$40 \mathrm{~Hz}$ PFC stimulation induced hyperactivity in Thy1-Chr2 mice $\left(t_{(5)}=3.18 ; p=0.024\right.$ using FDR-corrected paired $t$ test $)$. Conversely, stimulation with the pyramidal neuron pattern had no effect on locomotor profiles during the $1 \mathrm{~min}$ stimulation period $\left(t_{(5)}=0.51 ; p=0.63\right.$ using FDR-corrected paired $t$ test; Fig. 1$)$.

\section{Low-frequency stimulation of PFC layer V neurons models an} acute antidepressant-like effect

Next, we examined whether direct stimulation of layer V-PFC projection neurons exhibited antidepressant-like properties. For these experiments, we used the stimulation pattern based on the prerecorded pyramidal neuron. We chose this stimulation pattern instead of higher-frequency stimulation patterns classically used in DBS (i.e., $>120 \mathrm{~Hz}$ ) for three reasons. First, the stimulation frequency used with the prerecorded neuron was consistent with the mean firing rate of PFC pyramidal neurons observed in other studies (Jones and Wilson, 2005). Second, higherfrequency PFC stimulation (i.e., $40 \mathrm{~Hz}$ ) induced forward locomotion in Thyl-Chr2 mice, presenting a major confound to 
a

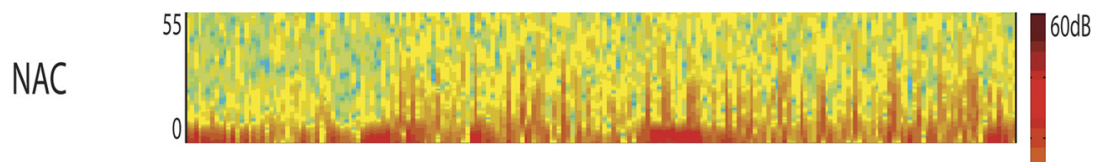

$B A$

VTA

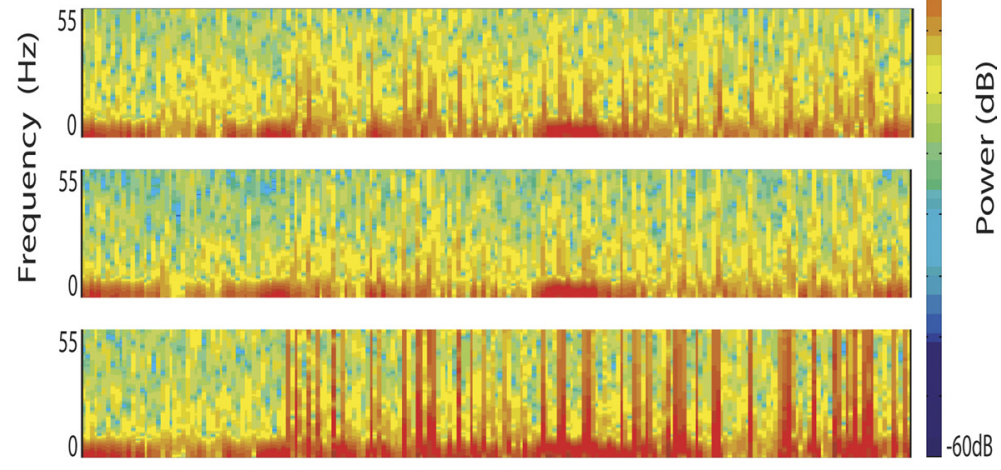

Laser

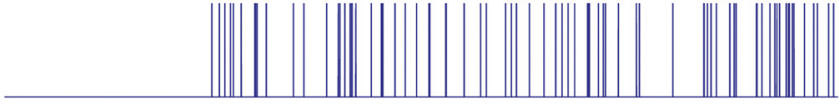

5s

b
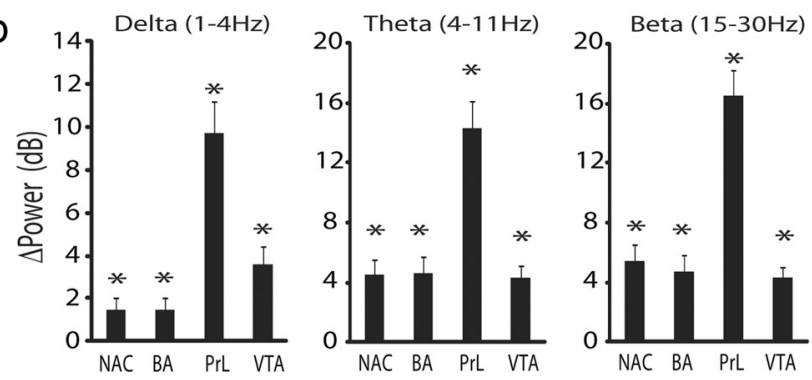

Figure 4. Optogenetic stimulation of cortical projection neurons increases oscillatory power across limbic brain areas. $\boldsymbol{a}$, LFP spectral trace during optogenetic stimulation of cortical projection neurons. $\boldsymbol{b}$, Change in oscillatory power during optogenetic cortical stimulation. ${ }^{*} p<0.05$ using Student's $t$ test, followed by an FDR correction for multiple comparisons; $n=8$ for all brain areas.

measuring the effect of layer V PFC stimulation on classic depression-related behaviors. Finally, previous studies have demonstrated that the fidelity of $\mathrm{Chr} 2$ stimulation is significantly limited above $40 \mathrm{~Hz}$ (Gunaydin et al., 2010).

Seven Thy1-Chr2 mice and their WT littermate controls were implanted with optogenetic stimulating fibers in PrL, and mice were subjected to a classic forced-swim test during PrL stimulation. For these experiments, animals were stimulated with the 1 min pattern used in our initial behavioral experiments repeated over the course of the $5 \mathrm{~min}$ behavioral experiments (acute stimulation). Our results indicated that stimulated Thy1-Chr2 mice displayed significantly lower immobility times compared with their stimulated WT littermate controls during the forced-swim test [two-way ANOVA of genotype $\times$ stimulation found significant genotype $\times$ stimulation effects $\left(F_{(1,27)}=8.36, p=0.008\right)$; post hoc tests using Bonferroni's-corrected Student's $t$ test found significant genotype effects (immobility time, $32.4 \pm 7.3$ and $6.4 \pm 2.5 \mathrm{~s}$ for stimulated Thy1-Chr2 and their WT littermates, respectively; $t_{(12)}=3.65 ; p=0.003 ; n=7$ mice per genotype) $]$. No differences in immobility time were observed between nonstimulated Thy1-Chr2 mice and their littermate controls (immobility time, $153.9 \pm 7.9$ and $133.8 \pm 11.6$ s for Thy $1-\mathrm{Chr} 2$ and their WT littermates, respectively; $t_{(12)}=1.43 ; p=0.18$ using Bonferroni's-corrected Student's $t$ test; $n=7$ mice per genotype;

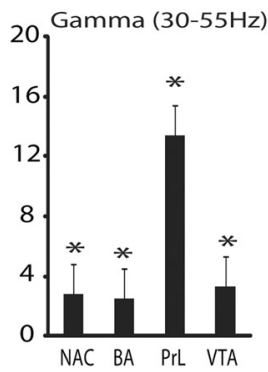

note that these mice were not implanted with stimulating fibers before the forced-swim test). Thy1-Chr2 mice stimulated with the PrL neuron pattern also traveled greater distances in an open-field test compared with their littermate controls [two-way ANOVA of genotype $\times$ stimulation revealed a significant genotype $\times$ stimulation interaction effect $\left.\left(F_{(1,24)}=5.22, p=0.0328\right)\right]$. Post hoc tests of distance traveled found significant genotype effects within the stimulated group of mice (distance traveled, $1324.0 \pm 57.9$ and $942.1 \pm 113.7 \mathrm{~s}$ for Thy1-Chr2 and their WT littermates, respectively; $t_{(9)}=3.16 ; p=0.01$ using Bonferroni's-corrected Student's $t$ test; $n=5-7$ mice per genotype) but not within the nonstimulated group (distance traveled, $975.3 \pm 84.7$ and $1045.7 \pm 119.6$ $s$ for Thyl-Chr2 and their WT littermates, respectively; $t_{(12)}=0.48 ; p=0.64$ using Bonferroni's-corrected Student's $t$ test; $n=5-7$ mice per genotype; note that these mice were not implanted with stimulating fibers before the open-field test). Notably, cortical stimulation did not directly induce hyperactivity, because no statistical differences were observed between stimulated Thyl-Chr2 mice and WT littermate controls during the first minute of open-field exploration $\left(t_{(9)}=\right.$ 1.32; $p=0.22$ using Student's $t$ test). Rather, cortical stimulation in Thyl$\mathrm{Chr} 2$ mice sustained the initial behavioral response observed in both WT and ThylChr2 mice (Fig. 1d). This effect was consistent with the psychomotor activating properties exhibited by antidepressant agents (Brocco et al., 2002).

\section{PFC stimulation models a chronic antidepressant-like effect} in socially stressed mice

Chronic subordination stress is most often followed by the expression of a long-lasting behavioral syndrome in mice that is characterized by social avoidance, impaired coping responses to other environmental stressors, and anxiety-like behaviors (Krishnan et al., 2007). Notably, these stress-induced behaviors can be reversed by chronic, but not acute, administration of conventional antidepressants (Berton et al., 2006). Thus, we also examined whether chronic PrL stimulation was sufficient to model an antidepressant-like response in chronically stressed mice. Thy1$\mathrm{Chr} 2$ mice and their WT littermate controls were subjected to $15 \mathrm{~d}$ of chronic subordination stress. Following chronic stress exposure, WT and Thy1-Chr2 mice were repeatedly stimulated with the same 5 min pattern used during the other depressionrelated tests. Stimulations were delivered daily over 14 consecutive days. WT and Thy1-Chr2 mice were tested $10 \mathrm{~d}$ after the last stimulation in a social interaction test to quantify their social avoidance and an EPM test to quantify their anxiety-related behavior. No additional cortical stimulations were performed during these tests. Chronically stressed and stimulated Thy1-Chr2 
a

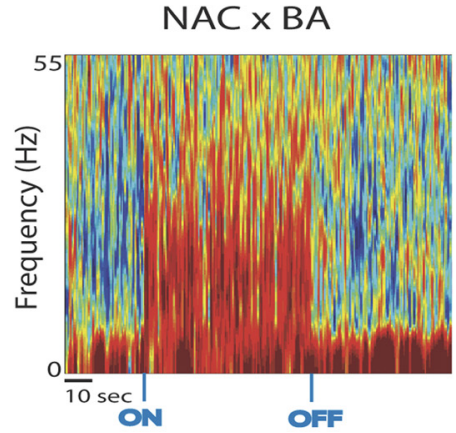

b

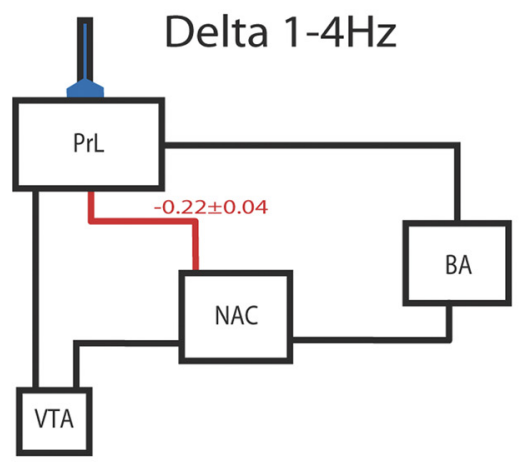

NAC $\times$ VTA

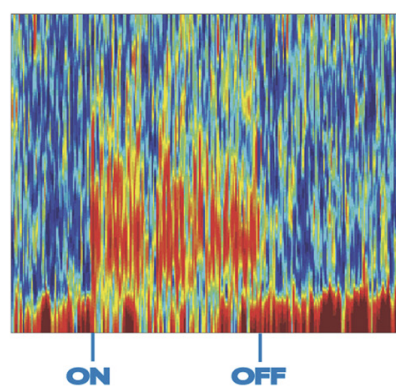

NAC $\times \operatorname{PrL}$

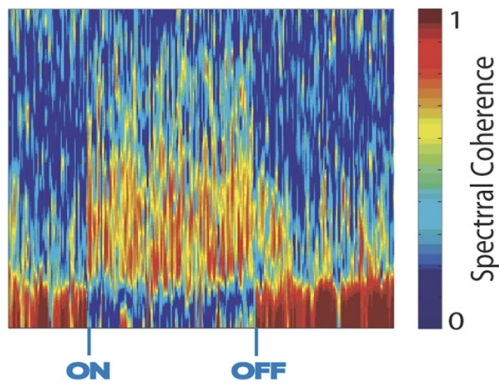

Beta $15-30 \mathrm{~Hz}$

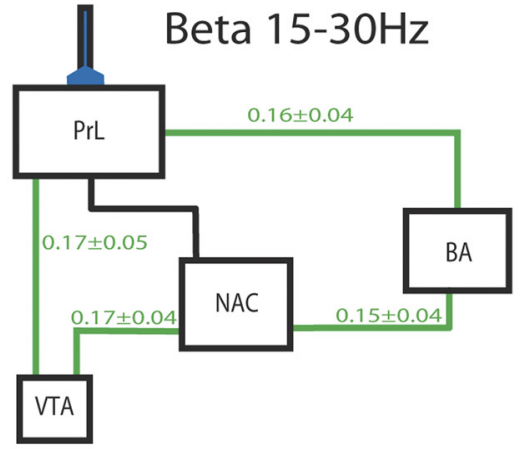

C

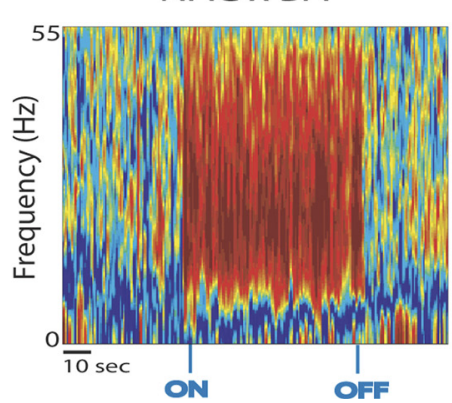

NAC $\times$ VTA

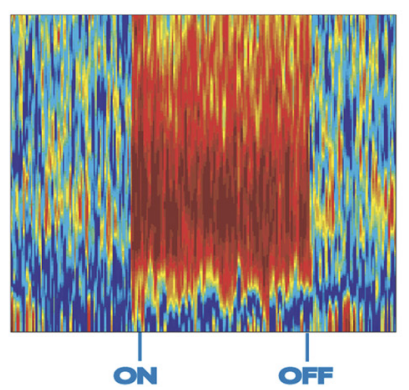

NAC $\times$ PrL

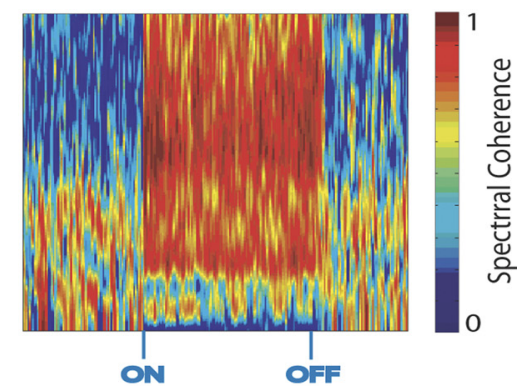

Figure 5. Cortical stimulation modulates spectral synchrony across distributed limbic circuits. $\boldsymbol{a}$, Spectral coherence plots generated for LFP pairs recorded across limbic brain areas during PrL stimulation. $\boldsymbol{b}$, Circuits that demonstrated significant changes in synchrony during cortical stimulation are shown in green (increases) or red (decreases) with their respective percentage coherence change from baseline. $p<0.05$ using Student's $t$ test, followed by an FDR correction for multiple comparisons; $n=8$ for all brain area pairs. $c$, Spectral coherence plots generated for LFP pairs recorded across limbic brain areas in a mouse during fixed frequency PrL stimulation at $4 \mathrm{~Hz}$ (note that $4 \mathrm{~Hz}$ stimulation tended to enhance limbic beta synchrony).

mice exhibited decreased social interaction scores compared with single-housed control mice $\left(t_{(11)}=5.74 ; p=0.00013\right.$ using Student's $t$ test); however, no significant differences in social interaction $\left(t_{(12)}=0.35 ; p=0.73\right.$ using Student's $t$ test) or open-field exploration $\left(t_{(12)}=0.75 ; p=0.47\right.$ using Student's $t$ test $)$ were observed between Thy1-Chr2 mice and their chronically stressed and stimulated WT littermate controls (Fig. 2a,b). Conversely, chronically stressed and stimulated Thyl-Chr2 mice spent significantly more time in the open arms of the EPM compared with WT mice [two-way ANOVA of genotype $\times$ stress condition revealed a significant genotype $\times$ stress interaction effect $\left(F_{(1,26)}=8.06\right.$, $p=0.0093)$; and post hoc tests using Student's $t$ test $\left(t_{(12)}=2.66\right.$; $p=0.012$ ) revealed a significant genotype effect in the chronically stressed group; Fig. $2 c$, left]. Together, these experiments demonstrate that chronic stimulation of PFC projection neurons induces an anxiolytic-like effect in mice exposed to chronic social subordination stress. Furthermore, this effect is long lasting given that it is observed 10-14 d after the last session of cortical stimulation. Notably, no significant differences in EPM open-arm time were observed between chronically stimulated Thy1-Chr2 mice and their WT littermate controls that were not exposed to chronic social defeat stress [post hoc tests using Student's $t$ test $\left(t_{(11)}=1.16 ; p=0.27\right)$ found no significant genotype effect in the nonstressed group; Fig. $2 c$, right].

\section{Layer V PFC stimulation drives limbic beta synchrony}

Twelve Thy1-Chr2 mice were implanted with a fiber-optic stimulating cannula directly above anterior PrL (an anatomical subdivision of medial PFC). Microwire array recording electrodes were also implanted across multiple limbic brain regions, including PrL, NAc, BA, and VTA. Mice implanted with the microwire electrode assemblies recovered well and behaved normally after surgery, allowing us to concurrently record LFP and unit activity across entire limbic circuits in awake, non-restrained conditions during direct stimulation of cortical projecting neurons (Fig. $3 a, b)$. The same spike train pattern used for our behavioral experiments was used to drive the stimulating laser (Fig. 3c). Using this stimulating pattern, we found that direct activation of PrL projection neurons was sufficient to enhance LFP oscillatory 
a

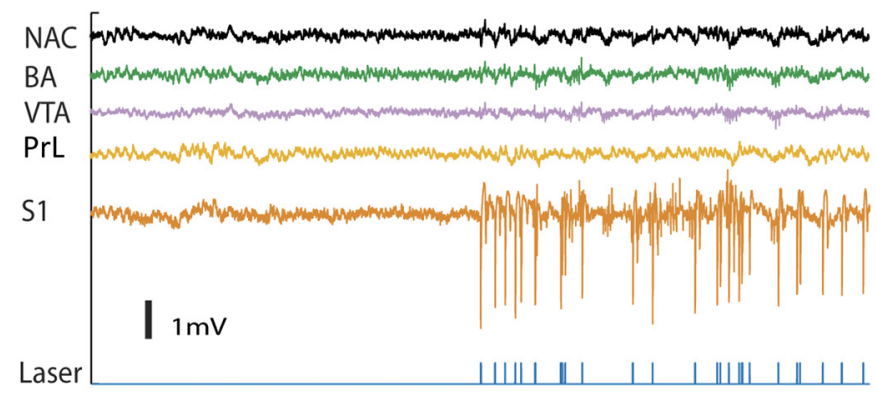

$\mathrm{NAC} \times \mathrm{BA}$
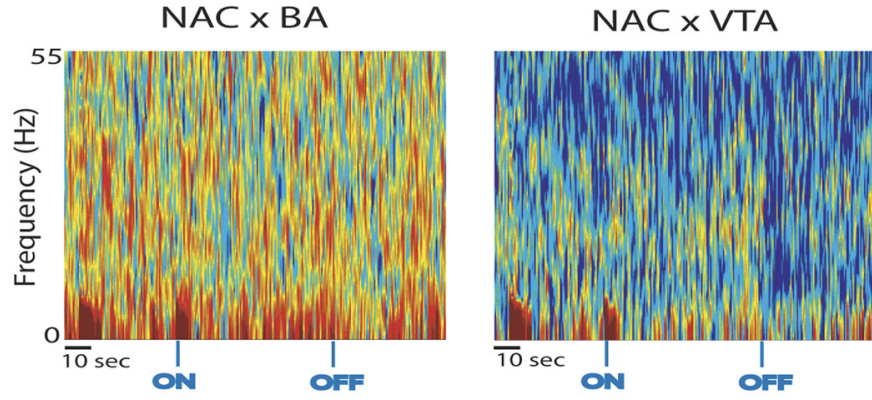

b
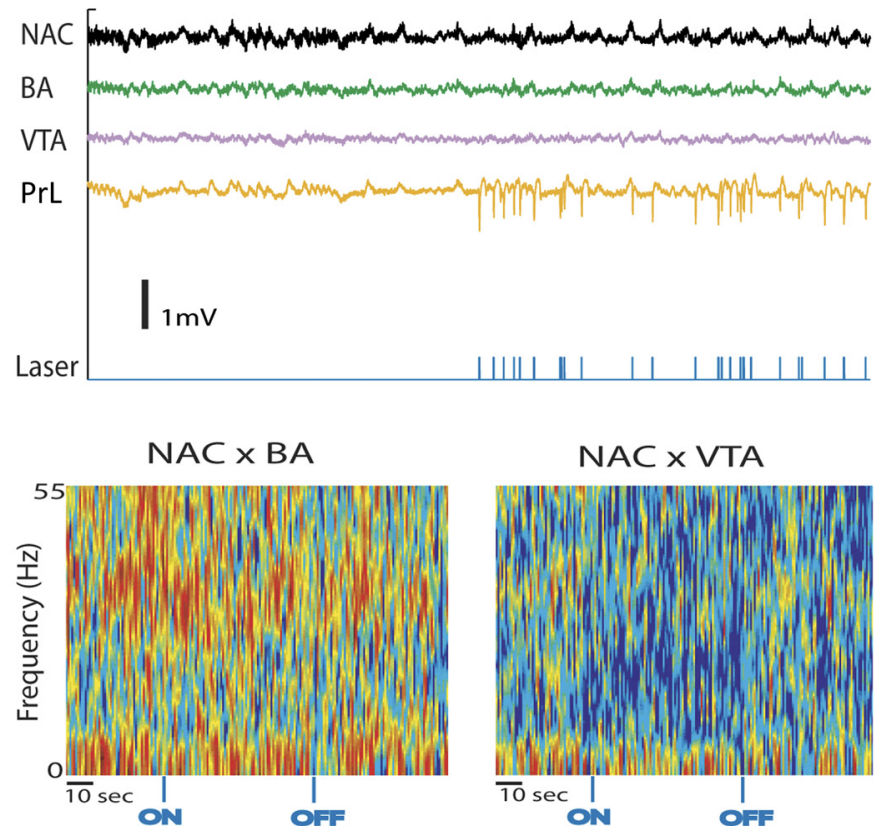

$\mathrm{NAC} \times \mathrm{PrL}$
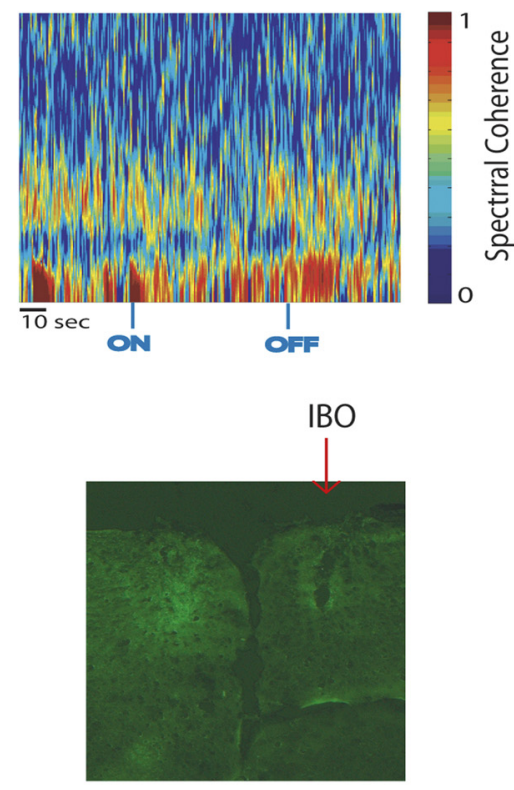

$\mathrm{NAC} \times \mathrm{PrL}$

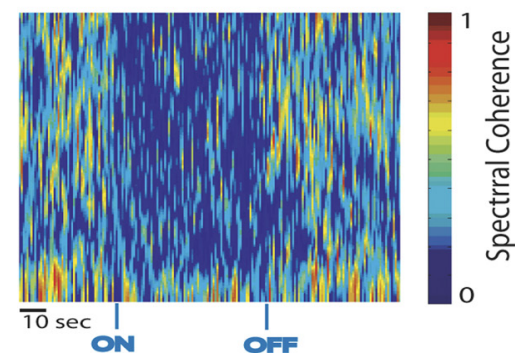

Figure 6. Stimulation of cortical projection neurons is necessary to enhance limbic synchrony. $\boldsymbol{a}$, LFP activity and limbic synchrony during S1 stimulation in a Thy1-Chr2 mouse ( $n=1)$. $\boldsymbol{b}$, Example LFP activity and limbic synchrony during PrL stimulation in a Thy1-Chr2 mouse pretreated with ibotenic acid $(n=2)$. Example histological image of PrL in Thy1-Chr2 mouse treated unilaterally with ibotenic acid. Note the decreased eYPF expression in the hemisphere treated with ibotenic acid (IBO).

power across all of the limbic brain regions we recorded $(p<0.05$ for all comparisons across brain areas and frequency bands examined; see Fig. 4). Notably, these observations were not attributable to stimulus artifact introduced by the direct effect of light exposure on the PrL electrode tips (Cardin et al., 2009), because they were not observed in WT mice subjected to the same stimulation and recording protocol (Fig. 3d).

LFP synchrony has been implicated as a neurophysiological correlate of brain circuit function (Seidenbecher et al., 2003; Jones and Wilson, 2005; Dzirasa et al., 2009; Adhikari et al., 2010). Because direct PrL stimulation modulated limbic oscillatory power, we also quantified changes in spectral coherence across LFP pairs during the recording session. Interestingly, we found that PrL stimulation suppressed PrL-NAc delta synchrony, and drove beta synchrony across the entire limbic circuit ( $p<0.05$ for all comparisons using FDR-corrected $t$ test; Fig. 5). Conversely, optogenetic stimulation of PrL projection neurons had no effect on theta or gamma synchrony across the circuit. Notably, because the mean firing rate of the exogenous cell used to drive the stimulating laser was $4.02 \mathrm{~Hz}$ and PrL stimulation at a fixed $4 \mathrm{~Hz}$ frequency tended to enhance limbic beta synchrony as well (Fig. $5 c$ ), the changes in beta synchrony observed across limbic circuits during cortical stimulation did not simply reflect the activation pattern of the stimulating laser. Rather, the changes in synchrony observed across this frequency range likely corresponded with the activation of neural networks responsible for 
the modulation of physiologically relevant circuits. Importantly, no enhancement of limbic beta synchrony was observed in a mouse pretreated with ibotenic acid in PrL or during stimulation of S1 or using the same PrL neuron-based pattern (i.e., $4.02 \mathrm{~Hz}$; Fig. 6). Together, these findings demonstrate that direct PrL stimulation induces circuit-selective changes in limbic neural oscillatory dynamics.

After demonstrating that direct stimulation of PrL projection neurons is sufficient to modulate limbic oscillatory power and the synchronization of limbic brain networks, we examined whether these changes were accompanied by changes in the timing of unit firing across limbic brain areas. For these experiments, PrL was stimulated at a frequency of $0.1 \mathrm{~Hz}$. Neurophysiological activity was then recorded for an additional $20 \mathrm{~min}$, and perievent firing rate histograms were calculated relative to each light pulse. Our findings indicated that $73.7 \%$ of the remote limbic neurons (101 of 137 neurons) displayed significant changes in their firing rates after single-pulse PrL stimulation (Fig. 7; for example of remote units modulated by single-pulse PrL stimulation, see Fig. 8). Effects differed widely within and across brains regions, with some units decreasing their firing rate after PrL stimulation, some units increasing their firing rate after PrL stimulation, and other units exhibiting both increases and decreases in their firing rates at various temporal delays after PrL stimulation. In several cases, unit activity changes could be observed $>150 \mathrm{~ms}$ after light pulses. Notably, 80.3\% (110 of 137) of the units analyzed exhibited stimulation-induced changes in their firing rates that correlated with locally recorded light-induced evoked potentials [i.e., light-triggered averages (LTAs) of LFP activity recorded from the same microwire as each unit], providing strong evidence that the limbic oscillatory changes observed after cortical stimulation were locally relevant. Several of the neurons recorded exhibited higher firing rates during temporal offsets consistent with the positive evoked response in LTA signals (Type A), whereas others exhibited higher firing rates during periods of the stronger negative evoked response (Type B). These different response patterns may reflect circuit-based response properties based on the profile of afferent connections that modulate the activity of each unit. When we examined the profile of population of neurons recorded within each region, we found that Type A BA neurons exhibited a significantly higher correlation with their local LTAs than Type B BA neurons (although no significant difference was observed in the proportion of Type A and Type B BA neurons; $p=0.015$ using Wilcoxon's rank-sum test; $p>0.05$ using $Z$ test, followed by FDR correction; Fig. 8). No significant differences were observed in the LTA coupling strength of Type A and Type B neurons across any of the other brain areas examined $(p=$ 0.20 and 0.07 using Wilcoxon's rank-sum test for NAc and
VTA neurons, respectively); however, a significantly higher proportion of Type A neurons was observed in NAc and VTA ( $p<0.05$ using $Z$ test, followed by FDR correction). Together, these results raise the hypothesis that PrL efferents may preferentially activate BA, NAc, and VTA inhibitory networks because Type A neurons (by definition) exhibit higher firing rates at time points in which the LFP was more hyperpolarized (more positive extracellular potential). Altogether, these results demonstrate that direct stimulation of PrL modulates neural oscillatory power, oscillatory phase timing, cross-area synchrony, and unit activity across vast limbic circuits responsible for mood regulation, affective control, fear and reward processing, and circadian regulation. Importantly, LFPs recorded concurrently from distinct brain areas within a mouse did not exhibit identical stimulation-locked responses (as would be expected if the remote signals resulted from electrical artifacts introduced by activating the laser; Fig. 9), the temporal nature of the remote evoked responses did not correspond with the distance of each site from the stimulating fiber (as would be expected in the case of volume conduction of the high-amplitude PrL signals that follow light stimulation), and the evoked responses were consistent with local unit activity. Thus, these neurophysiological changes were not attributable to stimulation artifact or the volume conduction of the high-amplitude PrL signals.

Finally, we examined the effect of PrL stimulation on the expression of the immediate early gene c-fos across limbic brain areas. When we compared stimulated Thy1-Chr2 mice and their nonstimulated Thy1-Chr2 littermates, we found that PrL stimu- 
a
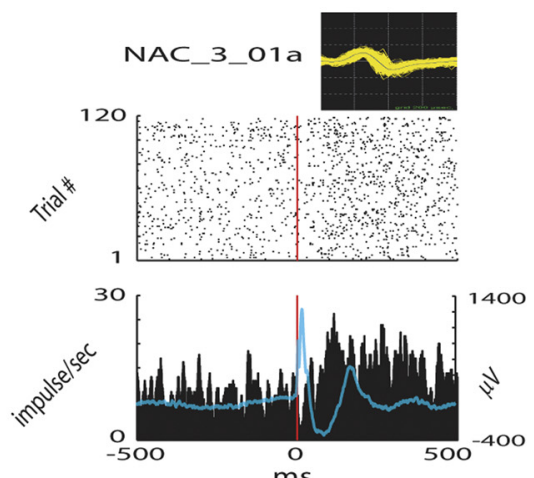

ms
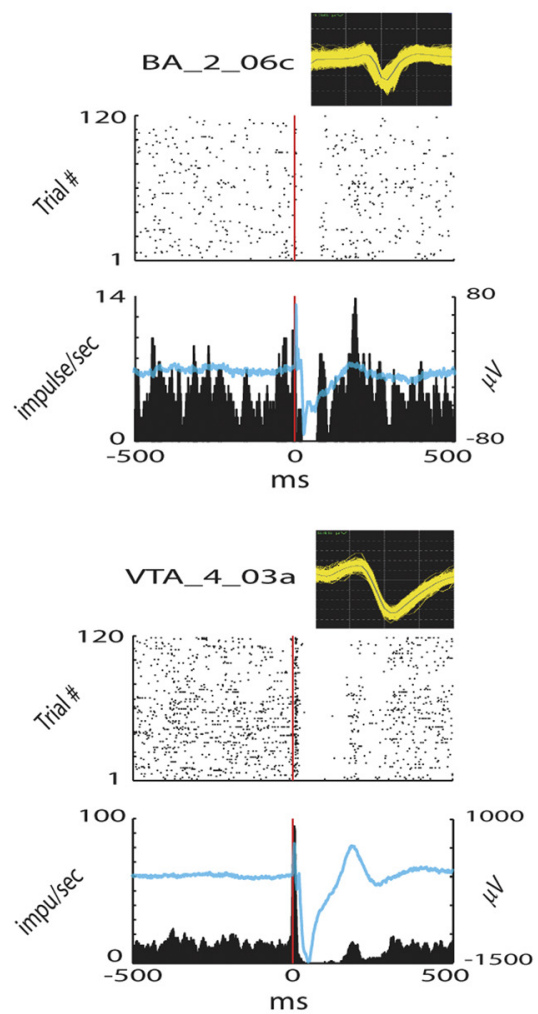
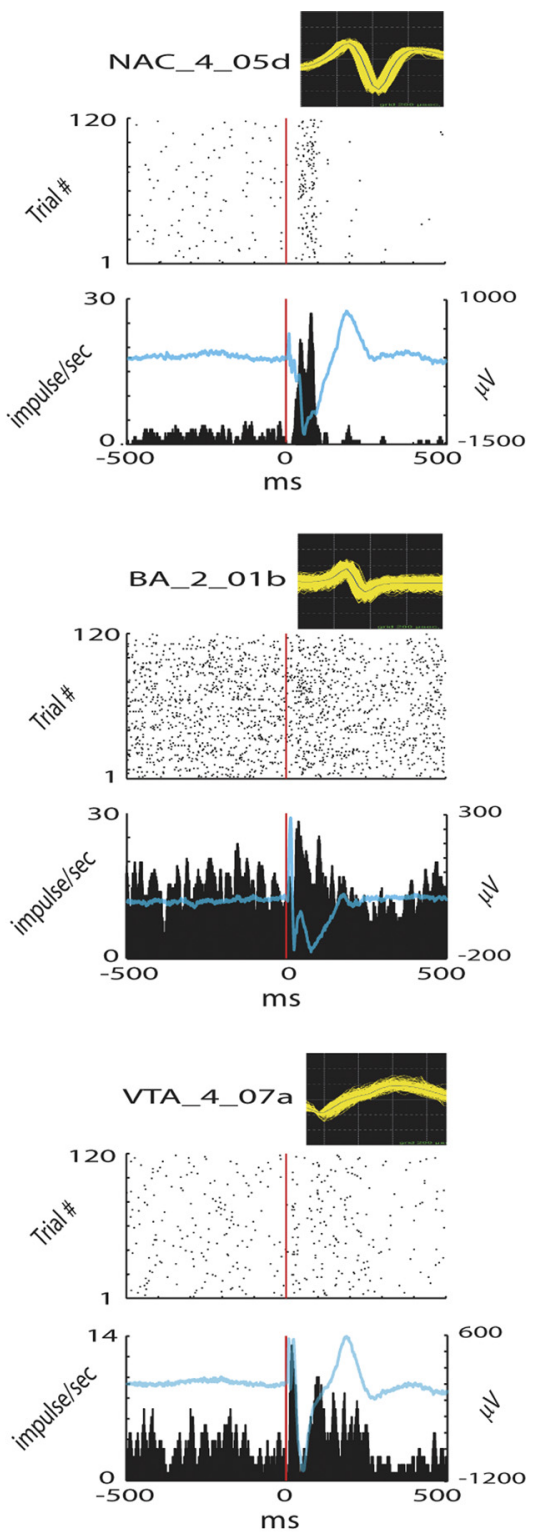
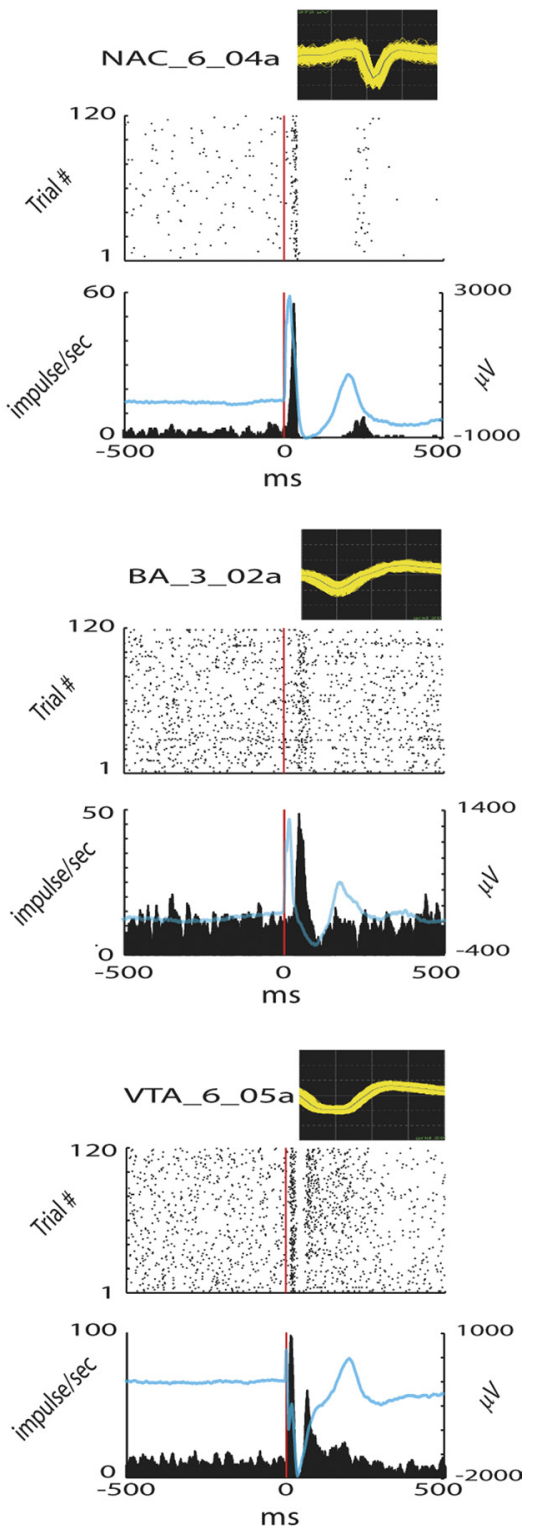

b

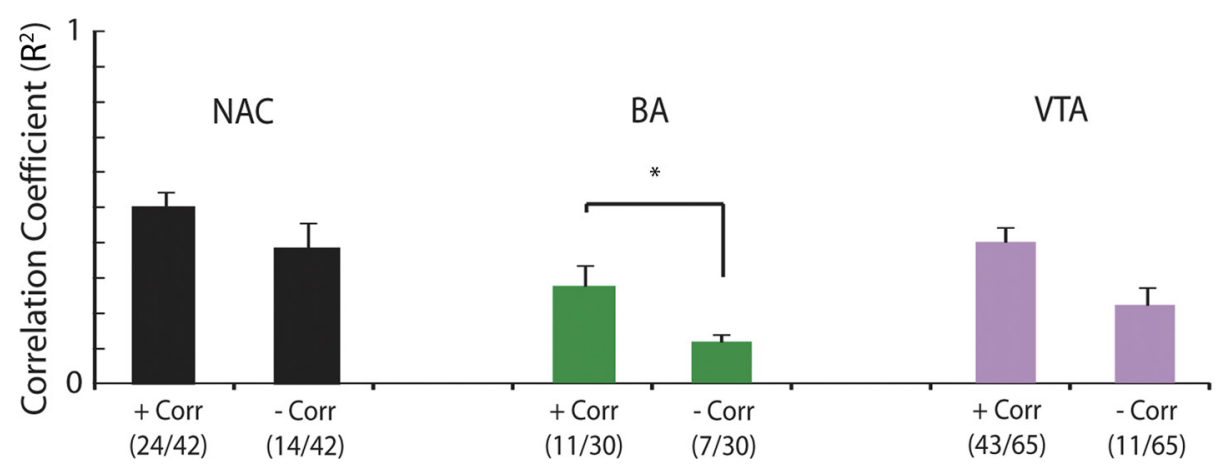

Figure 8. Cortical stimulation synchronizes unit activity across limbic circuits. PrL was stimulated at $0.1 \mathrm{~Hz}$ for 20 min for a total of 120 trials. $\boldsymbol{a}$, Each plot depicts a spike waveform ( $800 \mu$ s width, top), the perievent spike raster plot (middle), and the perievent firing rate time histogram (bottom) for the same neuron during cortical stimulation. Time 0 (red line) is the time of cortical stimulation during each trial. A total of 78.6\% of NAc neurons (33 of 42), 53.3\% of BA neurons (16 of 30), and 80.0\% of VTA neurons (52 of 65) were significantly modulated by cortical stimulation. Blue lines represent LTA functions calculated from LFPs recorded simultaneously from the same microwire as each isolated unit. $\boldsymbol{b}, A$ total of $90.5 \%$ of NAc neurons ( 38 of 42 ), $60.0 \%$ of BA neurons ( 18 of 30 ), and $83.1 \%$ of VTA neurons (54 of 65) displayed activities that positively correlated (+Corr; Type A; see NAC_6_04a for example) or negatively correlated (-Corr; Type B; see NAC_4_05d for example) with locally recorded LTAs after single-pulse cortical stimulation. ${ }^{*} p<0.05$ using Mann-Whitney $U$ test. 
lation tended to increase c-fos expression across multiple limbic brain areas, although only PrL and NAc reached statistical significance $(p<0.05$ using unpaired $t$ test; Fig. 10). Notably, these data provide unequivocal evidence that PrL stimulation modulates the firing rate of neurons distributed across target areas of PrL efferents.

\section{Discussion}

MDD is a heterogeneous multifactorial neuropsychiatric illness characterized by profound changes in sleep, affect, interests, and outlook on life (American Psychiatric Association, 2000; Akil et al., 2010). Although it has been difficult to recapitulate all of the salient aspects of MDD in a single animal (Krishnan and Nestler, 2008; Nestler and Hyman, 2010), animal models have served as powerful tools to investigate the mechanism of action of modalities used to ameliorate depressive symptoms (Nestler et al., 2002; Charney and Manji, 2004; Jinno and Kosaka, 2009; Akil et al., 2010). Here we show that the direct activation of PrL projection systems is sufficient to modulate oscillatory activity across limbic networks and induce limbic beta synchrony. Moreover, we show that the oscillatory changes observed across limbic brain areas during cortical stimulation directly correlate with changes in local unit activity and that cortical stimulation differentially affects local networks and c-fos expression across each of the limbic brain regions we examined. Finally, we demonstrate the chronic PrL stimulation modifies affectrelated behavior in chronically stressed animals.

High-frequency electrical stimulation of infralimbic (IL) cortex (i.e., DBS) promotes antidepressant-like properties in rodents subjected to a forced-swim test (Hamani et al., 2010). Notably, IL DBS continues to induce an antidepressant-like response after the ablation of local neurons within IL cortex, suggesting that electrical stimulation of pass through fibers (such as those originating from PrL) may play a role in mediating the antidepressant-like effects of IL DBS. Our findings demonstrate that similar responses can be recapitulated by directly stimulating excitatory projection neurons in PrL. Thy1-Chr2 (line 18) mice express the ChR2-YFP fusion protein in layer $\mathrm{V}$ cortical neurons and several subcortical brain areas (Arenkiel et al., 2007). Although the Thy1-Chr2 transgenics may express Chr2 in the axon terminals of several PrL afferents, the neurophysiological effects we observe during PrL light stimulation is unlikely attributable to antidromic activation of these fibers. First, BA projections to PrL do not express Chr2 in the line 18 mice. Second, DA neurons that project from VTA to PrL do not express Chr2 in line 18 mice. Third, there are no direct projections from striatum (i.e., NAc) to PrL in rodents. Fourth, PrL efferents provide monosynaptic or polysynaptic input to many of the subcortical brain regions that
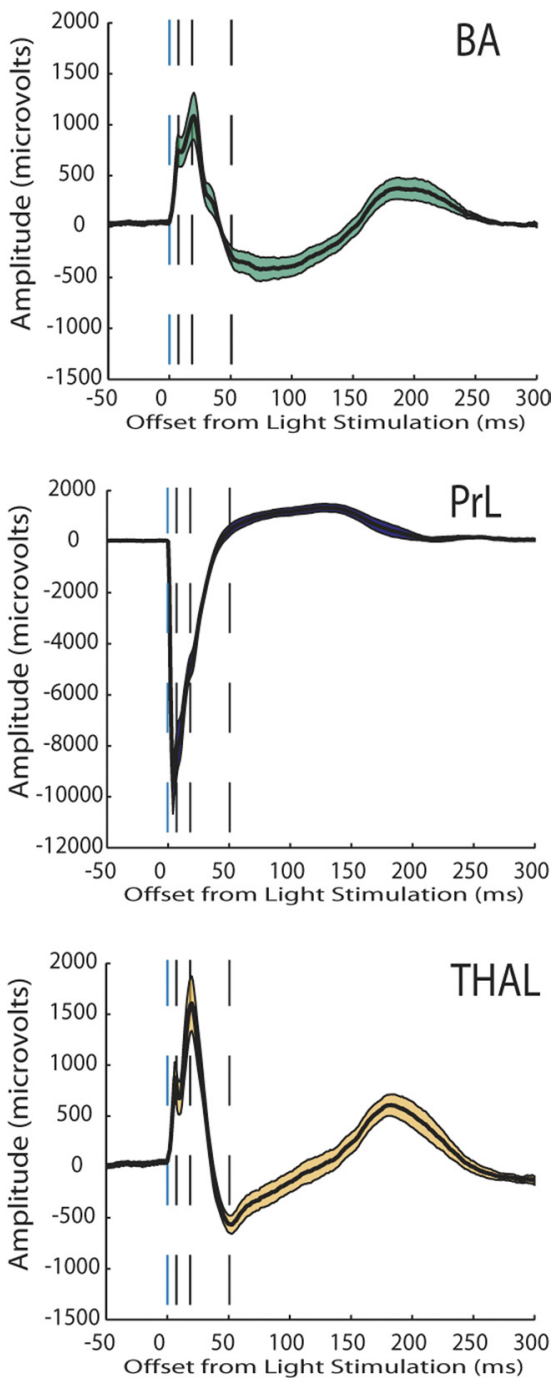

Figure 9. Evoked potential recorded from limbic brain areas during low-frequency cortical stimulation $(0.1 \mathrm{~Hz})$. Evoked potentials are shown as the mean \pm SEM for all of the LFP channels recorded across each structure within a single mouse during a single trial. This mouse had recording electrodes implanted in dorsal raphe (DR) (AP, $-4.5 \mathrm{~mm} ; \mathrm{ML}, 0.3 \mathrm{~mm}$; and DV, $-2.25 \mathrm{~mm}$ from ma) and medial dorsal thalamus (THAL) (AP, $-1.6 \mathrm{~mm} ; \mathrm{ML}, 0.3 \mathrm{~mm} ;$ and DV, $-2.9 \mathrm{~mm}$ from bregma) in addition to the othe brain areas described in this study. Note that several brain areas that were most distal to the stimulation site (i.e., DR and VTA) exhibited maximum/minimum potential peaks that occurred before the proximal brain areas (i.e., NAc).

express Chr2 in the Thy1-Chr2 (line 18) mice, and the efferent output from PrL to these subcortical brain regions far exceeds the afferent input from these brain regions to PrL (Douglas and Martin, 2004; Logothetis, 2008). Finally, pretreatment with ibotenic acid [which induces excitotoxic lesions in local neurons while sparing pass-through fibers (Hamani et al., 2010)] suppresses the enhancement of limbic synchrony observed during PrL stimulation. Thus, we are confident that the neurophysiological and behavioral changes induced by PrL stimulation are attributable to the activation of descending cortical efferents and not antidromic activation of PrL afferents.

Decreased immobility time on the forced-swim test after the acute administration of various pharmacological agents is widely used as a model for predicting the clinical efficacy of antidepressants. Although our findings show that acute PrL activation recapitulates the effect of antidepressants on the forced-swim test and the psychomotor activating effect of antidepressants in the open field (Brocco et al., 2002), it remains unclear the extent to which the forced-swim test in and of itself actually models MDD in 
a
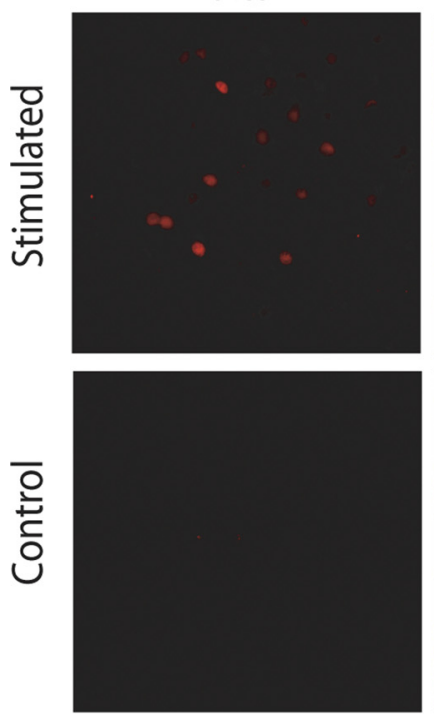

b

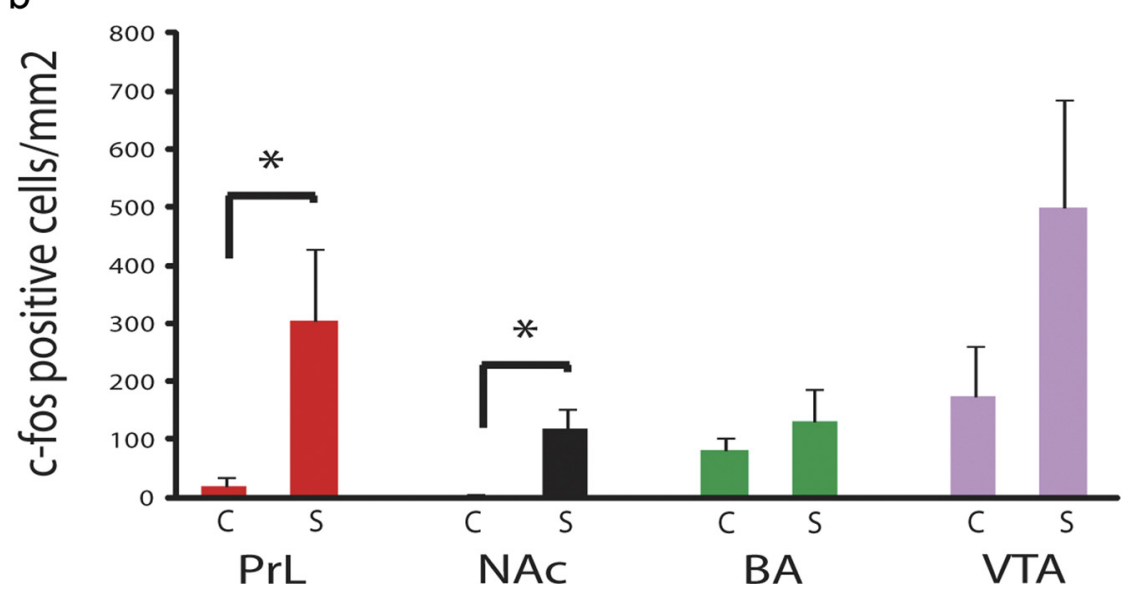

Figure 10. Stimulation-induced c-fos expression. $\boldsymbol{a}, \mathrm{c}$-fos immunostaining (red) in the NAc; cell nuclei are identified by DAPI staining (blue). Images are representative of three images taken from each of three separate brains at $40 \times$ magnification. $\boldsymbol{b}$, Quantification of c-fos-positive cells across PrL, NAc, BA, and VTA in Thy1-Chr2 mice after 5 min of PrL stimulation and in nonstimulated Thy1-Chr2 mice. ${ }^{*} p<0.05$ using $t$ test; $n=6$ mice per condition.

humans (Nestler and Hyman, 2010). Conversely, chronic subordination stress comprises a model for engendering depressivelike behaviors with ethological, face, and predictive validity (Miczek et al., 2008).

Chronic cortical stimulation as used in the current study produced a robust anxiolytic-like response in mice exposed to chronic subordination stress as measured by the EPM, although not in social interaction behavior. Notably, chronic administration of antidepressive agents, including selective serotonin reuptake inhibitors, also induces selective anxiolytic effects (Stein, 1998). Although our previous findings demonstrated that highfrequency non-cell-type-selective PFC stimulation reduced social avoidance in mice exposed to chronic subordination stress, this type of stimulation had no effect on anxiety-related behavior (Covington et al., 2010). These divergent findings may ultimately be attributable to the different $\mathrm{PrL}$ areas targeted in the two studies, the different circuit-wide effects induced by the high- and low-frequency stimulation parameters, or the cell-type-specific stimulation protocol used in this study. Notably, chronic cortical stimulation did not induce an anxiolytic-like response in non- stressed Thy1-Chr2 mice. This demonstrates that our stimulation paradigm targets the pathological anxiety-related brain changes that result from exposure to chronic stress but not normal fear processing that occurs in nonstressed mice. Because the anxiolytic effect that followed chronic cortical stimulation in stressed mice was observed 10-14 d after the last cortical stimulation, our findings suggest that our chronic stimulation protocol induced plastic changes across affective circuits that are modified by stress. Nevertheless, additional experiments will be necessary to definitively test this hypothesis.

Cross-structural neural oscillatory synchrony has gained attention as a potential mechanism through which the brain binds the activity of populations of neurons distributed across many cortical and subcortical structures to generate behaviors. For example, studies demonstrate that hippocampus and PFC oscillations synchronize during anxiety (Adhikari et al., 2010) and spatial-cognitive processes (Jones and Wilson, 2005; Dzirasa et al., 2009). Together, these studies suggest that the longrange synchronization of neural oscillatory activity may play a role in coordinating activity between structures that define broad neural circuits. Notably, changes in cross-structural synchrony have been implicated in mediating the behavioral manifestations observed across other brain disorders, such as Parkinson's disease (Fuentes et al., 2009), schizophrenia (Sigurdsson et al., 2010), bipolar disorder (Dzirasa et al., 2011b), and depression (Sheline et al., 2010).

Here we use a multicircuit neurophysiological recording approach (Dzirasa et al., 2011a) to characterize activity across limbic brain circuits during optogenetic stimulation of PFC projection neurons in freely behaving mice. Our results demonstrated that low-frequency stimulation of PFC projection neurons (i.e., $4.02 \mathrm{~Hz}$ stimulation pattern) selectively enhanced beta synchrony and suppressed delta synchrony across widely distributed limbic circuits. These selective changes in delta and beta synchrony were observed despite the fact that PFC stimulation enhanced oscillatory power across all of the frequencies (delta, theta, beta, and gamma) and brain areas examined in this study. Interestingly, functional changes across limbic beta networks have been linked to antidepressant response profiles in human depressed subjects (Salvadore et al., 2010). Given that the PFC layer V stimulation models an acute antidepressant-like effect across several depression-related behavioral tests and an antidepressant-like effect (i.e., anxiolytic) in mice exposed to chronic social defeat stress, our findings raise the hypothesis that modulation of limbic network (delta and beta) synchrony may play an important role in the antidepressant-like effect of direct electrical or magnetic stimulation of PFC in MDD. Indeed, studies have suggested that cortical-limbic networks that regulate affective and cognitive processing overlap within a node of the PFC 
(i.e., the dorsal nexus), and alterations in synchrony between this node and several limbic brain areas have been described in MDD (Sheline et al., 2010). Nevertheless, additional studies in patients with MDD will be necessary to definitely test this hypothesis.

\section{Conclusions}

Overall, our findings provide strong support for the top-down modulation hypothesis proposed to underlie the mechanism of action of DBS and TMS in treatment refractory MDD (Mayberg, 2009). The unveiling of the circuit-based interactions between PFC and limbic brain regions, with millisecond resolution, holds promise toward greater understanding of the neurobiological underpinnings of MDD and the targeted therapeutics used to treat the disorder. Most importantly, these findings may ultimately serve to enhance the targeting of antidepressant therapies, including DBS and TMS, and they may facilitate the development of the optogenetic-based therapeutic approaches to target dysfunctional circuits in affective and anxiety disorders.

\section{References}

Adhikari A, Topiwala MA, Gordon JA (2010) Synchronized activity between the ventral hippocampus and the medial prefrontal cortex during anxiety. Neuron 65:257-269. CrossRef Medline

Akil H, Brenner S, Kandel E, Kendler KS, King MC, Scolnick E, Watson JD, Zoghbi HY (2010) Medicine. The future of psychiatric research: genomes and neural circuits. Science 327:1580-1581. CrossRef Medline

American Psychiatric Association (2000) Diagnostic and statistical manual of mental disorders DSM-IV-TR. Washington, DC: American Psychiatric Association.

Anikeeva P, Andalman AS, Witten I, Warden M, Goshen I, Grosenick L, Gunaydin LA, Frank LM, Deisseroth K (2012) Optetrode: a multichannel readout for optogenetic control in freely moving mice. Nat Neurosci 15:163-170. CrossRef Medline

Arenkiel BR, Peca J, Davison IG, Feliciano C, Deisseroth K, Augustine GJ, Ehlers MD, Feng G (2007) In vivo light-induced activation of neural circuitry in transgenic mice expressing channelrhodopsin-2. Neuron 54: 205-218. CrossRef Medline

Benjamini Y, Drai D, Elmer G, Kafkafi N, Golani I (2001) Controlling the false discovery rate in behavior genetics research. Behav Brain Res 125: 279-284. CrossRef Medline

Berton O, McClung CA, Dileone RJ, Krishnan V, Renthal W, Russo SJ, Graham D, Tsankova NM, Bolanos CA, Rios M, Monteggia LM, Self DW, Nestler EJ (2006) Essential role of BDNF in the mesolimbic dopamine pathway in social defeat stress. Science 311:864-868. CrossRef Medline

Blazer DG, Kessler RC, McGonagle KA, Swartz MS (1994) The prevalence and distribution of major depression in a national community sample: the National Comorbidity Survey. Am J Psychiatry 151:979-986. Medline

Brocco M, Dekeyne A, Veiga S, Girardon S, Millan MJ (2002) Induction of hyperlocomotion in mice exposed to a novel environment by inhibition of serotonin reuptake. A pharmacological characterization of diverse classes of antidepressant agents. Pharmacol Biochem Behav 71:667-680. CrossRef Medline

Cardin JA, Carlén M, Meletis K, Knoblich U, Zhang F, Deisseroth K, Tsai LH, Moore CI (2009) Driving fast-spiking cells induces gamma rhythm and controls sensory responses. Nature 459:663-667. CrossRef Medline

Charney DS, Manji HK (2004) Life stress, genes, and depression: multiple pathways lead to increased risk and new opportunities for intervention. Sci STKE 2004:re5. CrossRef Medline

Covington HE 3rd, Lobo MK, Maze I, Vialou V, Hyman JM, Zaman S, LaPlant Q, Mouzon E, Ghose S, Tamminga CA, Neve RL, Deisseroth K, Nestler EJ (2010) Antidepressant effect of optogenetic stimulation of the medial prefrontal cortex. J Neurosci 30:16082-16090. CrossRef Medline

Douglas RJ, Martin KA (2004) Neuronal circuits of the neocortex. Annu Rev Neurosci 27:419-451. CrossRef Medline

Drevets WC (2001) Neuroimaging and neuropathological studies of depression: implications for the cognitive-emotional features of mood disorders. Curr Opin Neurobiol 11:240-249. CrossRef Medline

Dzirasa K, Ramsey AJ, Takahashi DY, Stapleton J, Potes JM, Williams JK,
Gainetdinov RR, Sameshima K, Caron MG, Nicolelis MA (2009) Hyperdopaminergia and NMDA receptor hypofunction disrupt neural phase signaling. J Neurosci 29:8215-8224. CrossRef Medline

Dzirasa K, Fuentes R, Kumar S, Potes JM, Nicolelis MA (2011a) Chronic in vivo multi-circuit neurophysiological recordings in mice. J Neurosci Methods 195:36-46. CrossRef Medline

Dzirasa K, McGarity DL, Bhattacharya A, Kumar S, Takahashi JS, Dunson D, McClung CA, Nicolelis MA (2011b) Impaired limbic gamma oscillatory synchrony during anxiety-related behavior in a genetic mouse model of bipolar mania. J Neurosci 31:6449-6456. CrossRef Medline

Eaton WW, Shao H, Nestadt G, Lee HB, Bienvenu OJ, Zandi P (2008) Population-based study of first onset and chronicity in major depressive disorder. Arch Gen Psychiatry 65:513-520. CrossRef Medline

Fuentes R, Petersson P, Siesser WB, Caron MG, Nicolelis MA (2009) Spinal cord stimulation restores locomotion in animal models of Parkinson's disease. Science 323:1578-1582. CrossRef Medline

George MS, Lisanby SH, Sackeim HA (1999) Transcranial magnetic stimulation: applications in neuropsychiatry. Arch Gen Psychiatry 56:300-311. CrossRef Medline

George MS, Lisanby SH, Avery D, McDonald WM, Durkalski V, Pavlicova M, Anderson B, Nahas Z, Bulow P, Zarkowski P, Holtzheimer PE 3rd, Schwartz T, Sackeim HA (2010) Daily left prefrontal transcranial magnetic stimulation therapy for major depressive disorder: a shamcontrolled randomized trial. Arch Gen Psychiatry 67:507-516. CrossRef Medline

Gunaydin LA, Yizhar O, Berndt A, Sohal VS, Deisseroth K, Hegemann P (2010) Ultrafast optogenetic control. Nat Neurosci 13:387-392. CrossRef Medline

Hamani C, Diwan M, Macedo CE, Brandão ML, Shumake J, Gonzalez-Lima F, Raymond R, Lozano AM, Fletcher PJ, Nobrega JN (2010) Antidepressant-like effects of medial prefrontal cortex deep brain stimulation in rats. Biol Psychiatry 67:117-124. CrossRef Medline

Jin X, Costa RM (2010) Start/stop signals emerge in nigrostriatal circuits during sequence learning. Nature 466:457-462. CrossRef Medline

Jinno S, Kosaka T (2009) Neuronal circuit-dependent alterations in expression of two isoforms of glutamic acid decarboxylase in the hippocampus following electroconvulsive shock: a stereology-based study. Hippocampus 19:1130-1141. CrossRef Medline

Jones MW, Wilson MA (2005) Theta rhythms coordinate hippocampalprefrontal interactions in a spatial memory task. PLoS Biol 3:e402. CrossRef Medline

Kahn I, Desai M, Knoblich U, Bernstein J, Henninger M, Graybiel AM, Boyden ES, Buckner RL, Moore CI (2011) Characterization of the functional MRI response temporal linearity via optical control of neocortical pyramidal neurons. J Neurosci 31:15086-15091. CrossRef Medline

Kessler RC, McGonagle KA, Zhao S, Nelson CB, Hughes M, Eshleman S, Wittchen HU, Kendler KS (1994) Lifetime and 12-month prevalence of DSM-III-R psychiatric disorders in the United States. Results from the National Comorbidity Survey. Arch Gen Psychiatry 51:8-19. CrossRef Medline

Krishnan V, Nestler EJ (2008) The molecular neurobiology of depression. Nature 455:894-902. CrossRef Medline

Krishnan V, Han MH, Graham DL, Berton O, Renthal W, Russo SJ, Laplant Q, Graham A, Lutter M, Lagace DC, Ghose S, Reister R, Tannous P, Green TA, Neve RL, Chakravarty S, Kumar A, Eisch AJ, Self DW, Lee FS, Tamminga CA, Cooper DC, Gershenfeld HK, Nestler EJ (2007) Molecular adaptations underlying susceptibility and resistance to social defeat in brain reward regions. Cell 131:391-404. CrossRef Medline

Liotti M, Mayberg HS (2001) The role of functional neuroimaging in the neuropsychology of depression. J Clin Exp Neuropsychol 23:121-136. CrossRef Medline

Logothetis NK (2008) What we can do and what we cannot do with fMRI. Nature 453:869-878. CrossRef Medline

Mathers CD, Loncar D (2006) Projections of global mortality and burden of disease from 2002 to 2030. PLoS Med 3:e442. CrossRef Medline

Mayberg HS (2009) Targeted electrode-based modulation of neural circuits for depression. J Clin Invest 119:717-725. CrossRef Medline

Mayberg HS, Lozano AM, Voon V, McNeely HE, Seminowicz D, Hamani C, Schwalb JM, Kennedy SH (2005) Deep brain stimulation for treatmentresistant depression. Neuron 45:651-660. CrossRef Medline

Miczek KA, Yap JJ, Covington HE 3rd (2008) Social stress, therapeutics and 
drug abuse: preclinical models of escalated and depressed intake. Pharmacol Ther 120:102-128. CrossRef Medline

Monteggia LM, Luikart B, Barrot M, Theobold D, Malkovska I, Nef S, Parada LF, Nestler EJ (2007) Brain-derived neurotrophic factor conditional knockouts show gender differences in depression-related behaviors. Biol Psychiatry 61:187-197. CrossRef Medline

Mueller TI, Leon AC, Keller MB, Solomon DA, Endicott J, Coryell W, Warshaw M, Maser JD (1999) Recurrence after recovery from major depressive disorder during 15 years of observational follow-up. Am J Psychiatry 156:1000-1006. Medline

Nestler EJ, Hyman SE (2010) Animal models of neuropsychiatric disorders. Nat Neurosci 13:1161-1169. CrossRef Medline

Nestler EJ, Barrot M, DiLeone RJ, Eisch AJ, Gold SJ, Monteggia LM (2002) Neurobiology of depression. Neuron 34:13-25. CrossRef Medline

Ressler KJ, Mayberg HS (2007) Targeting abnormal neural circuits in mood and anxiety disorders: from the laboratory to the clinic. Nat Neurosci 10:1116-1124. CrossRef Medline

Salvadore G, Cornwell BR, Sambataro F, Latov D, Colon-Rosario V, Carver F, Holroyd T, DiazGranados N, Machado-Vieira R, Grillon C, Drevets WC,
Zarate CA Jr (2010) Anterior cingulate desynchronization and functional connectivity with the amygdala during a working memory task predict rapid antidepressant response to ketamine. Neuropsychopharmacology 35:1415-1422. CrossRef Medline

Seidenbecher T, Laxmi TR, Stork O, Pape HC (2003) Amygdalar and hippocampal theta rhythm synchronization during fear memory retrieval. Science 301:846-850. CrossRef Medline

Sheline YI, Price JL, Yan Z, Mintun MA (2010) Resting-state functional MRI in depression unmasks increased connectivity between networks via the dorsal nexus. Proc Natl Acad Sci USA 107:11020-11025. CrossRef Medline

Sigurdsson T, Stark KL, Karayiorgou M, Gogos JA, Gordon JA (2010) Impaired hippocampal-prefrontal synchrony in a genetic mouse model of schizophrenia. Nature 464:763-767. CrossRef Medline

Stein MB (1998) Medication treatments for panic disorder and social phobia. Depress Anxiety 7:134-138. CrossRef Medline

Yizhar O, Fenno LE, Davidson TJ, Mogri M, Deisseroth K (2011) Optogenetics in neural systems. Neuron 71:9-34. CrossRef Medline 